\title{
Unravelling causal factors of maritime incidents and accidents
}

\author{
Romanas Puisa ${ }^{1}$, Lin Lin, Victor Bolbot, and Dracos Vassalos \\ Maritime Safety Research Centre \\ University of Strathclyde, Glasgow, Scotland
}

\begin{abstract}
Lessons from maritime accidents are conventionally used to inform safety improvements in design and operation of ships. However, this process is only as good as the core understanding derived from accident analysis is. The current explanation of accidents is limited to direct and contributing causal factors, whereas the role of a wider socio-technical context that has given rise to causal mechanisms behind major maritime accidents in recent years is left unexplained. The paper describes analysis results of maritime incidents and accidents occurred over the last decade with passenger ships, with the purpose to illuminate the prevailing causal factors, not least the systemic ones. The results show where the weak links in maritime safety control are (e.g., interactions between ship operators and equipment manufacturers), what their role in accident causation is, and how they can be strengthened. The study seeks to provide valuable input for enhancements in overall maritime safety control and proactive safety management at the ship and shipping company levels.
\end{abstract}

Keywords: accident, incident, causation, maritime, safety, risk, STAMP, CAST, systemic factors, classification

\section{Introduction}

Good safety records are prerequisite for achieving strategic goals, including profits and continuous existence, of any shipping company. However, serious maritime incidents and accidents remain rife. The last decade was replete with dreadful calamities, not least the sinking of cruise ship Costa Concordia and ferry MV Sewol (KMST, 2014; MIT, 2013). The decades before, were equally depressing (e.g., MS Herald of Free Enterprise, Estonia, and Express Samina). At the same time, the safety assurance on modern ships is getting more complicated, partly due to the conventional safety strategy defence-in-depth (Carroll, 1998), which requires redundancies and multiple layers of protection, and partly due to new digital technologies, e.g. dynamic barrier management (Pitblado et al., 2016), which introduces extra layers of defence, new interactions and weak couplings (Twomey, 2017).

Given the mediocre safety records, it can be argued that the answer lies in currently used fundamentals and practices of accident analysis. As in other similar industries such as aviation, maritime accident investigations serve to inform evolutionary improvements in design and operational practices. This means that high quality of accident investigations is instrumental in improving safety. The accident analysis process, its outcome and response to the accident are dependent on an accident model assumed, i.e. the conceptual understanding of how accidents occur (Benner Jr, 1985; Svenson, 1999). The currently used investigation manuals are based on the Swiss cheese model by Reason (Reason, 1997), i.e. a complex linear accident model where the importance of unsafe acts is accentuated and the underlying causes of the events are practically ignored other than a lack of safety barriers (slices of the cheese) aimed to prevent their propagation (Lundberg et al., 2009). Thus, the accident investigation remains mostly confined to the context in which proximate events occurred, barriers failed and the organisational factors involved (Schröder-Hinrichs et al., 2011).

It, hence, appears that the importance of wider systemic issues in accident etiology is insufficiently recognised, despite the evidence from many maritime incidents and accidents, as shown in this and other publications (Johnson and Holloway, 2007), and the solid theoretical basis, e.g. (Carroll, 1998; Leveson, 2011; Rasmussen, 1997), for them. Such evidence, for instance, points to systemic factors that insidiously degraded safety barriers, acting as their common cause failure and making the defence-in-depth ineffective. For instance, Kim et al. describe the accident with passenger ferry $M V$ Sewol where commercial pressures and lax regulatory control had disabled vital organisational and technical barriers, making the accident imminent (Kim et al., 2016a). According to the systems approach, accidents are a result of poor functioning of the safety control system as a whole, i.e. the presence of dysfunctional interactions between system elements and, therefore, inadequate enforcement of safety requirements and constraints (Leveson, 2011). Such inadequate interactions within the socio-technical system must be identified, analysed and

\footnotetext{
${ }^{1}$ Corresponding author. E-mail: r.puisa@strath.ac.uk
} 
remedied, regardless of whether their effect is direct and easily explainable, or it is uncertain or extra-organisational, as it happens with nonlinear, more distant — in time and space - causal factors.

With this in mind, the understanding of the contribution of the entire safety control system-regulators, insurers, manufactures and supplies, shipping companies, ships, equipment, etc.-becomes essential for prevention of accidents, incidents and other unwanted events. This requires going beyond proximate failures and flawed interactions at the ship and shipping company levels, as well as unhelpful assumptions that unfortunate events are mainly random and caused by "human erroneous actions", e.g. (EMSA, 2017). Hence, the exploration should seeks to answer the question why accidents could occur, extending the frontiers of current knowledge about the underlying causal mechanisms thereby (Figure 1). Attempts have been made to bridge this knowledge gap (Section 2), but the problem, alas, remains under-researched.

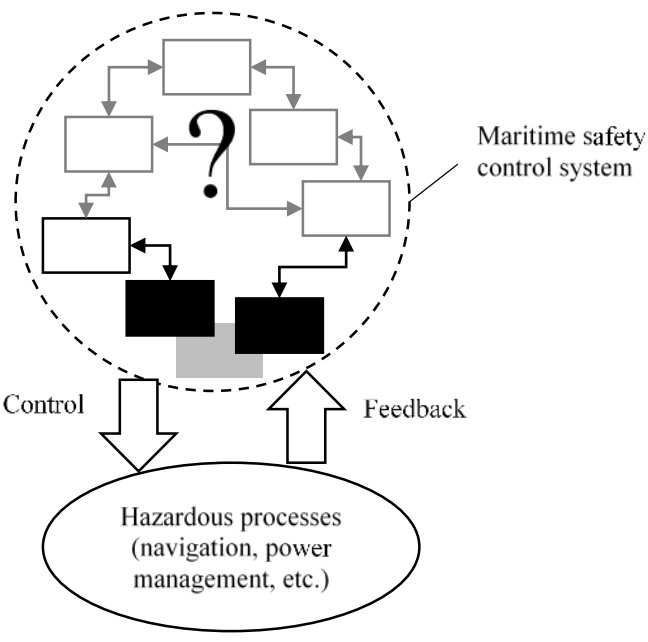

Figure 1: Dysfunctional interactions (inadequate safety enforcement) within the overall system

Hence, the purpose of this paper is to illuminate dysfunctional interactions within the entire system of maritime safety control, the interactions that gave rise to direct, contributing and systemic causal factors behind significant incident and accidents. To this end, we adopted the Systems-Theoretic Accident Model and Processes (STAMP) and its method for causal analysis called CAST (Leveson, 2011). We applied CAST to analyse 188 incident and accident reports, retrieving 1,250 instances of dysfunctional interactions in the system. We classified these interactions according to their cause and condition that made them dysfunction, and discussed the dominant flaws, i.e. weakest links in the maritime safety control. The analysis of the accident reports would often lead to richer and sometimes different explanations, typically involving new causal factors to those concluded in the investigations. Therefore, we also recorded the degree of dissimilarity between our findings and the conclusions in investigation reports, which we found to overlook both direct and contributing causal factors, let alone systemic ones.

The paper is organised as follows. Section 2 discussed methods and results applied so far to illuminate wider causal factors within the maritime safety control system. Section 3 explains the adopted methodology to achieve the objectives of the work (Section 3). Section 4 presents the results, which are then discussed in Section 5. The paper is concluded in Section 6.

\section{Related work}

The Human Factor Analysis and Classification System (HFACS) has been widely applied to enrich accident analysis with respect to human and wider organisational factors (Shappell and Wiegmann, 2012). Examples comprise general analysis (Celik and Cebi, 2009; Chen et al., 2013) and more specific ones, such as of machinery space fires and explosions (Schröder-Hinrichs et al. 2011), ship collisions (Chauvin et al., 2013), and, most recently, assessing the potential impact of unmanned vessels on safety (Wróbel et al., 2017). However, HFACS also rests on the Swiss cheese accident model and is used to label types of errors, problems, or poor decisions made by humans and organisations. However, HFACS remains inadequate for systemic causal analysis (Stringfellow, 2010).

Bayesian belief networks (BBN) have been widely used to incorporate managerial, regulatory and other actors of safety control, e.g. (Kristiansen, 2010; Mazaheri et al., 2016). However, being acyclic graphs, BBN cannot explicitly represent nonlinear interactions with feedback loops, which are an integral part of hazard control and risk management 
in general. For instance, the absence of feedback on correctness of applied control actions by crew or automation has led to many accidents, including the engine room fire on cruise ship Le Boreal (Section 3.4).

Systemic accident models have been most successful in exploring the safety control system beyond the ship and shipping company. For instance, the Accident Analyse Mapping (AcciMap) (Svedung and Rasmussen, 2002) has been applied to unravel systemic causes in the Sewol Ferry accident (Lee et al., 2017). The authors concluded that limiting blame to the Sewol's captain and its crewmembers was unfair, and the disaster was a result of a series of safety issues across different levels of the company, government and regulatory bodies. The CAST has also been applied to the same accident, resulting with analogous conclusions (Kim et al., 2016a).

In summary, the literature on identification of systemic causal factors within the entire system of maritime safety control is fairly limited. Comprehensive single case analyses exist, but no multiple case analysis that aggregates the causal factors into a single causal picture is available. In particular, we were unaware, at the time of writing this paper, of any multiple case analysis of maritime accidents or incidents with STAMP/CAST, as presented in this work.

\section{Methodology}

The adopted methodology rests on the accident analysis approach CAST that allows examining the entire sociotechnical system, taking into account both separate variables and systemic causal factors (Leveson, 2011; Leveson et al., 2003). The CAST has been applied to individual railway, aviation and maritime accidents (Kim et al., 2016b; Song et al., 2012; Wong, 2004); comparisons also exist with other accident analysis methods (Salmon et al., 2012; Underwood and Waterson, 2014). In contrast to other systemic models, STAMP better embodies systems thinking (Underwood and Waterson, 2014) and it is the most frequently cited (Underwood and Waterson, 2012).

The key element of CAST is a hierarchical control structure (HCS), which represents a functional model of the safety control system. The used HSC is explained in Section 3.1, with Section 3.2 addressing the use of it while analysing accident reports (Section 3.3). Section 3.4 provide an illustrative example of the analysis.

\subsection{Hierarchical safety control structure}

A hierarchical control structure (HCS) is a functional system model that is composed of feedback control loops. By system we are referring to the maritime safety control system, which includes international and state regulators, manufacturers, ship management companies, ships and their crew and equipment and many others (Kristiansen, 2005). An effective HCS will adequately enforce safety constraints on the behaviour of individual system elements (subsystems) and interactions between them, so that the hazards at the sharp-end are controlled. This is a systems view on accidents, which, hence, occur when such safety constraints are enforced inadequately.

Typically, the HCS is created for an existing system, including its specific elements and links between them. For instance, the system may be limited to a shipping company and, hence, the HCS would simply reflect the company's organogram with extra details (feedback loops, responsibilities and control actions, mental model variables, etc.) added. For instance, Leveson et al. has provided an application example to safety control within NASA (Leveson et al., 2005). The validity of such a single case HCS is verified against engineering and organisation documents, and in conversations with representative from the organisation. This paper performs a multi-case analysis, meaning that either a separate HCS is developed for each incident and accident or a generic HSC (GHSC) is established for all of them. Fortunately, a GHSC can be easily created for the maritime safety control system, because the HCS is built at the functional level ("What?"), as opposed to physical level ("How?"). At the functional level, the physical differences vanish between organisations of the same type, as well as between ships. This argument is further reinforced by the fact that the used dataset of accident reports was relatively uniform, containing only passenger ships within a relatively narrow range in size. The validity of the GHSC was further supported by the general guidelines (Leveson, 2011) and an array of example applications of STAMP where HSC diagrams have been developed, e.g. (Kim et al., 2016a; Wróbel et al., 2018).

The initial, high level GHSC version was informed by (Kristiansen, 2005) and the in-house domain knowledge on safety control in the maritime domain. Then, as the analysis of investigation reports was progressing, new system elements - prompted by the CAST analysis of individual reports-were added. For instance, if a new report dealt with navigational decisions on the bridge and the bridge had not been included into the GHSC yet, we would add it into the GHSC. The GHSC would contain all system elements for the next few reports until new elements (e.g., VTS, contract engineers) had to be added. Hence, the final GHSC contains an exhaustive set of system elements involved in causation of the analysed incidents and accidents, as shown in Figure 2. The GHSC contains control and feedback arrows between controlling and controlled components, as well as communication and coordination channels as 
dashed lines. Note, the dashed lines denote the absence of legal or organisational enforcement of safety constraints or request for feedback between the components. Hence, they represent advisory, consultative communication channels. Table 1 describes the roles of the key components (subsystems) in the GHSC in terms of the following characteristics (Leveson, 2011):

- Safety requirements and constraints to be enforced upon a component beneath, or communicated to other components.

- Controls, i.e. specific means of enforcing the constraints and thereby exerting control, or specific means of communicating safety information.

- Feedback, i.e. specific means of receiving the state of enforcement of the safety constraints, or specific means of communicating feedback.

- Context, i.e. disturbances in environment and behaviour-shaping factors that can undermine the enforcement of safety constraints or adequate communication.

It should be noted that although the GHSC is high level, it allows us to capture direct and contributing (organisational) causal factors such as unsafe actions by technology and humans, design errors, inadequate feedback from the bridge equipment to officers, etc. For instance, the GHSC contains automatic and passive controllers against oil leaks, hot surfaces etc., although they are aggregated into a single controller. Such aggregation is justifiable at the functional level, for these controllers perform essentially the same function-hazard mitigation-although not all of them would have feedback loops, for instance. Analogous simplifications were also applied to interactions between the system components. For instance, we show the links between the flag state and the company but omitted the interaction links between the flag state and the ship, as well as between the classification society and the ship. We assumed that the ship is nearly always involved in these interactions.

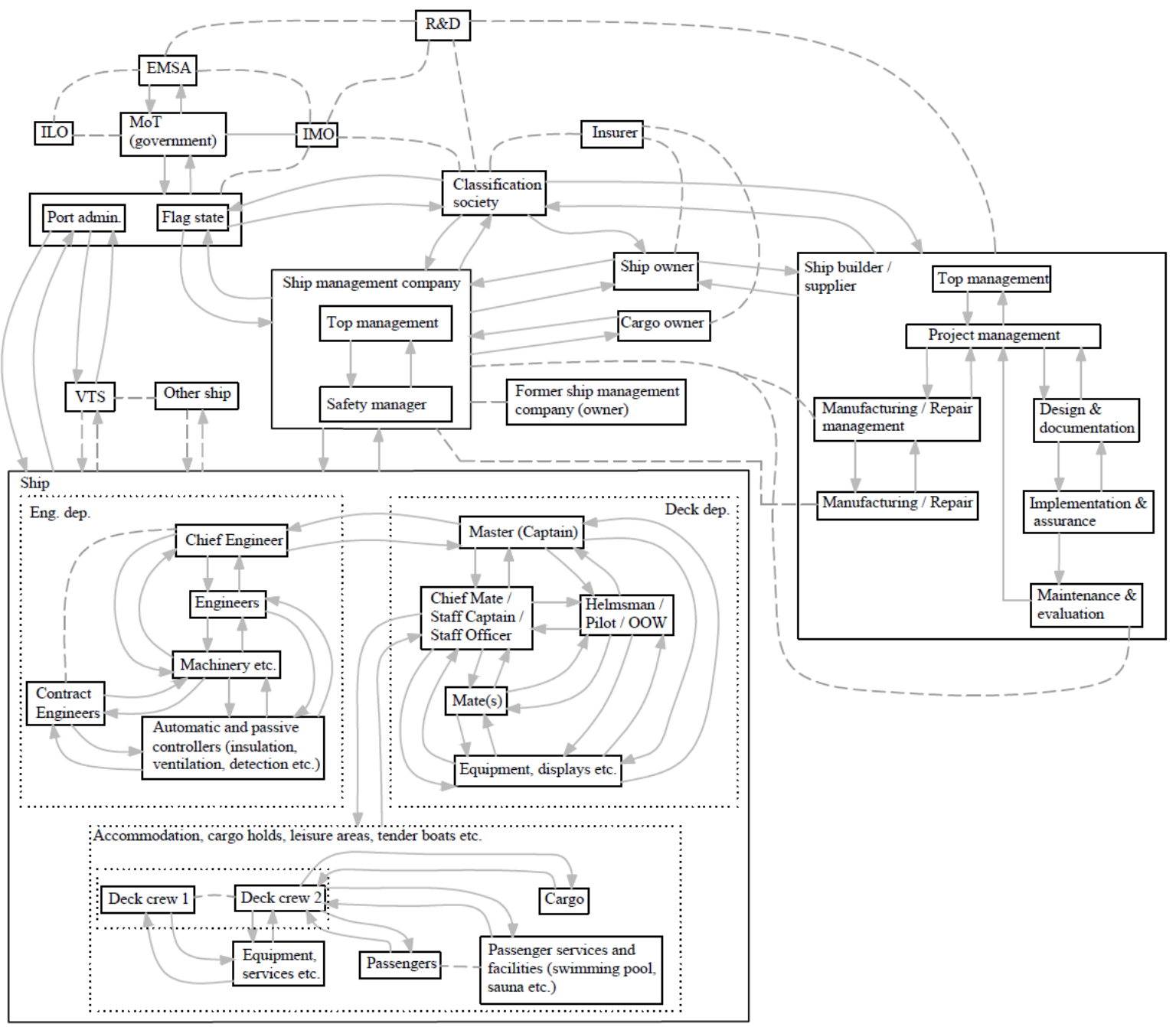

Figure 2: Generic safety control structure (maritime safety control system) 
Table 1: The role of individual components in the generic safety control structure (Kristiansen, 2005; STCW, 2010)

\begin{tabular}{|c|c|}
\hline Component (subsystem) & Purpose / safety role \\
\hline $\begin{array}{l}\text { International Maritime } \\
\text { Organisation (IMO) }\end{array}$ & $\begin{array}{l}\text { Develops and maintains a comprehensive regulatory } \\
\text { framework for safety shipping. }\end{array}$ \\
\hline $\begin{array}{l}\text { European Maritime } \\
\text { Safety Agency (EMSA) }\end{array}$ & $\begin{array}{l}\text { Provides technical assistance and support to the European } \\
\text { Commission and Member States in the development and } \\
\text { implementation of EU legislation on maritime safety, } \\
\text { pollution by ships and maritime security. }\end{array}$ \\
\hline $\begin{array}{l}\text { Ministry of } \\
\text { Transportation (MoT) }\end{array}$ & $\begin{array}{l}\text { Implements international safety regulations and directives } \\
\text { ratified/adopted by the state and EU parliament. }\end{array}$ \\
\hline $\begin{array}{l}\text { Flag state (maritime } \\
\text { administration) }\end{array}$ & $\begin{array}{l}\text { Enforcement of international safety regulations and issues } \\
\text { and controls safety certificates. Acts on behalf of the state. }\end{array}$ \\
\hline $\begin{array}{l}\text { Port administration / } \\
\text { authority }\end{array}$ & Responsible for safety in port and harbour approaches. \\
\hline $\begin{array}{l}\text { Vessel traffic services } \\
\text { (VTS) }\end{array}$ & $\begin{array}{l}\text { Marine traffic monitoring system established by harbour or } \\
\text { port authorities, similar to air traffic control for aircraft. }\end{array}$ \\
\hline Insurer & $\begin{array}{l}\text { Takes the main part in the risk on behalf of the ship } \\
\text { management company and cargo owner (i.e. vessel, cargo, } \\
\text { third party / protection and indemnity insurance). }\end{array}$ \\
\hline Classification society & $\begin{array}{l}\text { Control of technical standards on behalf of insurer during } \\
\text { design and operation. Undertakes safety control functions on } \\
\text { behalf of the flag state. }\end{array}$ \\
\hline Ship builder / supplier & $\begin{array}{l}\text { Builds the vessel/equipment to owner specification and } \\
\text { safety rules (statutory, industrial). Develops operational and } \\
\text { maintenance requirements with respect to safety. }\end{array}$ \\
\hline Ship owner & $\begin{array}{l}\text { Commissions and owns the vessel and decides whether } \\
\text { technical standards will be above minimal safety } \\
\text { requirements stipulated in the safety regulations. }\end{array}$ \\
\hline $\begin{array}{l}\text { Ship management } \\
\text { company }\end{array}$ & $\begin{array}{l}\text { Responsible for crewing, operation and maintenance of the } \\
\text { vessel on behalf of the shipowner. Offers other services like } \\
\text { inspection prior to purchase, supervision during building, } \\
\text { and ship lay-up solutions. }\end{array}$ \\
\hline Cargo owner & $\begin{array}{l}\text { Pays for the transport service and thereby also the quality } \\
\text { and safety of the vessel operation. }\end{array}$ \\
\hline Master (Captain) & $\begin{array}{l}\text { Superior responsibility for safe ship operation and } \\
\text { implementation of the SMS onboard. }\end{array}$ \\
\hline $\begin{array}{l}\text { Chief Mate / Staff } \\
\text { Captain / Safety Officer }\end{array}$ & $\begin{array}{l}\text { Second in command to Captain, a head of the deck } \\
\text { department and, customarily, a watchstander and is in charge } \\
\text { of the ship's cargo and deck crew. }\end{array}$ \\
\hline
\end{tabular}

Control and feedback mechanisms, context

Issues safety standards for construction, equipment and operation of ships. Receives feedback (incl. on $R \& D$ studies) from member states, inter-governmental organisations, non-governmental organisations. IMO has no power to enforce international safety regulations, and this task is passed to flag states.

Assists Member States with the practical implementation of EU legislation, organises appropriate training activities and promoting a dissemination of best practices in the EU, monitors classification societies, port state control and the development of ship reporting systems in Member States.

Enforces the implementation safety regulations and directives through national maritime administrations and port authorities, which report to MoT on safety related issues.

Flag state inspection of sailing vessels, survey and acceptance of new buildings, approval of manning, audit of SMS under ISM Code, monitor maritime traffic and dangerous cargoes, and investigate and analyse maritime accidents. Some of these functions (e.g. surveys and SMS audit) are normally contracted out to classification societies.

May control safety standards of vessels, and may deny access to substandard vessels.

Provides information, traffic organisation, and navigational assistance services to ships. VTS has an advisory role only.

May undertake independent assessment of the SMS quality of the ship management company.

Validates and reports that construction and operation of a vessel is in accordance with relevant safety standards and carry out regular surveys in service to ensure continuing compliance with the standards.

Tests the vessel and its systems, carries out repair work, communicates design assumptions and limitations to ship owners/operators in operational and maintenance manuals. Might receive feedback on the vessel / equipment operation and maintenance issues.

Selects crew or management company for crew and operation. Makes decisions regarding operational and organisational safety policies, communicating them to a ship management company (if different from the owner company).

Develops and maintains a safety management system (SMS) according to the ISM Code. Specifies responsibility, authority and interrelation of key personnel. Ensures adequate resources (incl. their training and selection) and shore-based support.

May undertake independent assessment of the SMS quality of the ship management company.

Motivate the crew, issue orders, verify adherence, review SMS, and reports events.

Supervision and crew training in areas such as safety, firefighting and flooding control, search and rescue. Oversees the loading, stowage, securing and unloading of cargoes, and the care of cargo during the voyage. Enforces all applicable safety regulations during navigation, loading and unloading in port. 


\begin{tabular}{|c|c|}
\hline Component (subsystem) & Purpose / safety role \\
\hline $\begin{array}{l}\text { Helmsman / Pilot / officer } \\
\text { of the watch (OOW) }\end{array}$ & Steers the ship / keeps watch on the bridge. \\
\hline Mate(s) & $\begin{array}{l}\text { The second mate is the third/ fourth in command and a } \\
\text { watchkeeping officer. Often is the medical officer and in } \\
\text { charge of maintaining distress signaling equipment. The } \\
\text { third mate is a watchstander and customarily the ship's safety } \\
\text { officer, focusing on firefighting equipment, lifeboats, and } \\
\text { various other emergency systems. }\end{array}$ \\
\hline Equipment, displays etc. & Navigation equipment/controls and aids on the bridge. \\
\hline Chief Engineer & $\begin{array}{l}\text { Oversees the engine/engineering department and is of equal } \\
\text { rank to the captain. Responsible for all operations and } \\
\text { maintenance of machinery equipment. Looks after safety of } \\
\text { subordinate maritime professionals working in the } \\
\text { engineering department. }\end{array}$ \\
\hline Engineers & $\begin{array}{l}\text { Second, third (sometimes electro-technical officer), fourth } \\
\text { engineers, and engine raitings responsible for supervising } \\
\text { the daily maintenance and operation of the engine } \\
\text { department. Reports directly to the chief engineer. }\end{array}$ \\
\hline Machinery etc. & $\begin{array}{l}\text { Generates power (mechanical, electrical, thermal) and } \\
\text { provides means for its safe utilisation onboard. }\end{array}$ \\
\hline $\begin{array}{l}\text { Automatic and passive } \\
\text { controllers (insulation, } \\
\text { ventilation, detection etc.) }\end{array}$ & $\begin{array}{l}\text { Safety systems (safety-instrumented systems) that detect and } \\
\text { control safety hazards (e.g., oil leaks, high temperature } \\
\text { surfaces) in the machinery spaces. }\end{array}$ \\
\hline Contract Engineers & $\begin{array}{l}\text { External engineers that typically represent manufactures of } \\
\text { installed equipment. }\end{array}$ \\
\hline Deck crew 1 and 2 & $\begin{array}{l}\text { Crewmembers looking after safety in accommodation, } \\
\text { public areas, cargo, and other areas. The crew is split into the } \\
\text { two groups to be able to represent dysfunctional interactions } \\
\text { between the crewmembers. }\end{array}$ \\
\hline Equipment, services etc. & $\begin{array}{l}\text { Equipment and services such as tender and pilot boats, cargo } \\
\text { loading facilities on cargo decks and others. }\end{array}$ \\
\hline
\end{tabular}

Control and feedback mechanisms, context

Responsible to Captain for the safety and security of the ship. Typically stands the 4-8 navigation watch as officer in-charge of the navigational watch, directing the bridge team.

Helm orders or commands fall into two categories: rudder commands and heading commands. Maintains clear and exact communication with the officer on the bridge for safe navigation and ship handling. Executes turns and the lookout reports dangers such as approaching ships.

Keep the watch, and ensure safety of the ship, its crew, and its cargo, according to all applicable regulations and safety management system. Mates generally stand watch with able seamen who act as helmsman and lookout.

Sends signals to actuators to change the speed, heading and other parameters of the vessel. Displays feedback information about the propulsion performance, ship speed, heading, global and relative positions etc., thereby supporting the save navigation.

Ensures compliance with the rules and regulations laid down by the flag state administration, IMO, and port state authorities. Carries out frequent inspections of equipment at regular intervals (lifesaving, fire preventing and other equipment). Issues standing orders for each crew member under his command, in accordance with the routine maintenance schedule as laid down by the Planned Maintenance System (PMS), which is prescribed by the manufactures. Makes sure that his crew attends all shipboard emergency drills and safety meetings, providing guidance (based on the company guidelines and procedures) to his crew during drills so that they know how to get out of an emergency situation safely in the minimum time possible. Must maintain a proper conduct with his crew members and address their queries and requirements to the best of his abilities.

In charge of boilers, fuel, auxiliary engines, condensate and feed systems by carrying out inspections, overhauls and repairs (planned and unplanned) according to technical manuals and a safety management system.

Physical control (passive and active) of hazardous physical processes such internal combustion. Provides feedback on physical parameters (pressure, temperature, voltage etc.) for safe operation and maintenance by crew.

Alert and alarm hazardous situations for the crew to take action. Actively supress hazards (e.g., fires).

Carry out onboard overhauls and repairs according to technical manuals and agreed safety procedures

Carry out active guidance and supervision of passenger and cargo safety, enforcing onboard procedures and policies of safety management. Accountable to the chief mate/staff captain/safety officer.

Provides crew and passenger transfer, cargo handling and other functions according to safety management procedures. 


\subsection{Analysis and classification}

Given an accident report, the CAST analysis follows the steps provided in Table 2.

Table 2: Generic CAST steps

\begin{tabular}{|c|c|}
\hline CAST step & Comments \\
\hline Identify the system(s) and hazard(s) involved in the loss & Taken from the report. \\
\hline $\begin{array}{l}\text { Identify the system safety constraints and system requirements associated } \\
\text { with that hazard. }\end{array}$ & Defined in Table 3. \\
\hline Determine the proximate events leading to the loss. & Taken from the report. \\
\hline $\begin{array}{l}\text { Analyse the loss at the physical system level. Identify the contribution of } \\
\text { hazard control flows to the loss. }\end{array}$ & Taken from the report. \\
\hline $\begin{array}{l}\text { Moving up the levels of the safety control structure, determine how and } \\
\text { why each successive higher level allowed or contributed to the inadequate } \\
\text { control at the current level. }\end{array}$ & \multirow{3}{*}{$\begin{array}{l}\text { Analysing the GHSC with the } \\
\text { guidance of the STAMP accident } \\
\text { model. }\end{array}$} \\
\hline Examine overall coordination and communication contributors to the loss. & \\
\hline $\begin{array}{l}\text { Determine the dynamics and changes in the system and the system control } \\
\text { structure relating to the loss and any weakening of the safety control over } \\
\text { time. }\end{array}$ & \\
\hline Gene & \\
\hline
\end{tabular}

As Table 2 indicates, the accident investigation reports already contained the basic information necessary for the analysis. Further information was inferred while exploring the GHCS. As the system elements in the GHCS are connected through functional causal links of control, feedback and communication channels, one can navigate from one element to the other, looking for answers to what and why has happened. The navigation is guided by a set of standard control flaws, which are related to issues with the control algorithm (purpose, safety role), process (mental) model, feedback and others (Table 1). The guiding principle behind the analysis is the assumption that people and organisations acted according to their best knowledge and ability, tools and information available at the time. That is, as long as the information about the controlled process state is accurate, training is right, and tools are appropriate, no unsafe action can be expected. This reflects the modern thinking that the human error is not the end outcome, but is the start of accident analysis (Dekker, 2014). The objective is to understand why people did what they did and why they could not act differently (Dekker, 2016). The same principle applies to machine controllers, but the questions are why designers (or regulators) made (or accepted) specific design assumptions which turned out to be wrong in a given situation.

The relevancy of explored interactions to an incident or accident at hand was determined based on the system-level hazards and corresponding safety constraints (Table 3). We used the definition of a safety hazards as "a system state or set of conditions that, together with a particular set of worst-case environmental conditions, will lead to a loss" (Leveson, 2011). The safety constraints are for clarity translated — through system engineering decomposition-into safety constraints of corresponding subsystems and individual components. 
Table 3: System-level hazards and constraints

\begin{tabular}{|c|c|}
\hline Hazards & Safety constraints and their decomposition at lower levels (subsystems) \\
\hline $\begin{array}{l}\text { H1. Design process } \\
\text { overlooks hazardous } \\
\text { scenarios that can } \\
\text { materialise during } \\
\text { operation and/or } \\
\text { maintenance }\end{array}$ & $\begin{array}{l}\text { C1. Risk identification in design must be adequate } \\
\text { - Design rules and standards must be up to date } \\
\text { - Pertinent design rules and standards must be used and applied correctly } \\
\text { - Hazard analysis methods must be adequate to identify all plausible safety hazards }\end{array}$ \\
\hline $\begin{array}{l}\text { H2. Manufacturing } \\
\text { deviates from the } \\
\text { design assumptions }\end{array}$ & $\begin{array}{l}\text { C2. Risk identification during manufacturing must be adequate } \\
\text { - Design assumptions must be well documented and communicated to manufactures } \\
\text { - Communication between designers and manufacturers must be adequate } \\
\text { - Design must be reviewed and validated/tested (e.g., sea trials) }\end{array}$ \\
\hline $\begin{array}{l}\text { H3. Onboard safety } \\
\text { management system } \\
\text { overlooks safety } \\
\text { hazards or does not } \\
\text { address them } \\
\text { adequately }\end{array}$ & $\begin{array}{l}\text { C3. Design assumptions and the actual operation must match (work as imagined vs. } \\
\text { work as done) } \\
\text { - Design assumptions must be well documented and communicated to the shipping } \\
\text { company } \\
\text { - Safety management system (SMS) must well reflect all design assumptions, not } \\
\text { least design limitations } \\
\text { C4. SMS must be verified, validated and constantly updated } \\
\text { - SMS must be approved by relevant authorities } \\
\text { - Design modifications and operational changes must be well documented and } \\
\text { - Hazard control measures (engineering and management) must be kept adequate } \\
\text { - New hazards must be identified and control measures timely implemented } \\
\text { - Crew must be well familiar with the ship and its safety procedures at all times } \\
\text { - Continuous communication/information exchange between the company and the } \\
\text { ship must be ensured }\end{array}$ \\
\hline
\end{tabular}

The analysis outcome is a set of dysfunctional interactions (e.g., inadequate control or feedback, or both) between the system elements. The dysfunctional interactions were classified as shown in Table 4.

Table 4: Hierarchical classification of dysfunctional interactions

\begin{tabular}{|c|c|c|}
\hline $\begin{array}{l}\text { Cause of dysfunctional } \\
\text { interaction (what/who failed?) }\end{array}$ & $\begin{array}{l}\text { Condition that made it } \\
\text { dysfunction (failure mode) }\end{array}$ & $\begin{array}{l}\text { Is included in investigation } \\
\text { conclusions? }\end{array}$ \\
\hline $\begin{array}{ll}\text { - } & \text { Control }(\downarrow) \\
\text { - } & \text { Feedback }(\uparrow) \\
\text { - } & \text { Both }(\downarrow \uparrow)^{2}\end{array}$ & $\begin{array}{ll}- & \text { Not given (N) } \\
- & \text { Wrong given (W) } \\
\text { - } & \text { Given too early/late (EL) } \\
\text { - } & \text { Stopping too soon / applying } \\
& \text { too long / given irregularly (S) } \\
\text { - } & \text { Unknown (U) } \\
\end{array}$ & $\begin{array}{ll}\text { - } & \text { Yes }(\mathrm{Y}) \\
\text { - } & \text { No }(\mathrm{N}) \\
\text { - } & \text { Partly (P) }\end{array}$ \\
\hline
\end{tabular}

The rightmost column in Table 4 was used to inform gap analysis, i.e. the gap between the accident causes reported in the investigations and revealed during the CAST analysis. The column indicates whether an observed accident cause was also captured in an accident investigation report at hand. In some reports, the same cause would be mentioned in investigation conclusions and recommendations and we would hence classify it as included. Other reports would contain an explicitly narrative of some causal factors, but not reflect them in conclusions and recommendations. We would classify such causal effect as partly included, provided they would lead to specific dysfunctional interactions during the CAST analysis.

The identified dysfunctional interactions show what actually happened immediately and long before an incident or accident. They would act as direct (proximate), contributing, or systemic factors in the accident causation (Johnson,

\footnotetext{
${ }^{2}$ It represents a situation when there is no clear-cut distinction between control and feedback.
} 
1980). This classification broadly reflects the intended scope of marine safety investigation (Res. MSC.255(84), 2008), and it was used to classify dysfunctional interactions according these broad and vaguely defined categories (Table 5).

Table 5: Classification of accident causes in three causal categories

\begin{tabular}{|l|l|l|l|}
\hline $\begin{array}{l}\text { Role of accident } \\
\text { causes }\end{array}$ & Determination & Context and traits & $\begin{array}{l}\text { Safety constraints / } \\
\text { requirements violated }\end{array}$ \\
\hline Direct factors (D) & $\begin{array}{l}\text { Found in accident } \\
\text { analysis }\end{array}$ & $\begin{array}{l}\text { Subsystem level. Proximate } \\
\text { events to the accident within the } \\
\text { same subsystem. }\end{array}$ & $\begin{array}{l}\text { Constraints on interaction } \\
\text { with physical hazardous } \\
\text { processes. }\end{array}$ \\
\hline $\begin{array}{l}\text { Contributing / } \\
\text { underlying factors } \\
\text { (C) }\end{array}$ & $\begin{array}{l}\text { Found in accident } \\
\text { analysis }\end{array}$ & $\begin{array}{l}\text { Inter-subsystem level. Within the } \\
\text { same subsystem or contiguous } \\
\text { subsystems. Have a linear effect } \\
\text { on proximate events. }\end{array}$ & $\begin{array}{l}\text { Constraints on procedures } \\
\text { and processes, and on } \\
\text { interaction between teams } \\
\text { and people. }\end{array}$ \\
\hline Systemic factors (S) & $\begin{array}{l}\text { Inferred during } \\
\text { accident analysis }\end{array}$ & $\begin{array}{l}\text { System level. Between } \\
\text { subsystems*. Have a nonlinear } \\
\text { effect on contributing and } \\
\text { proximate events. }\end{array}$ & $\begin{array}{l}\text { System safety constraints on } \\
\text { interaction between } \\
\text { subsystems. }\end{array}$ \\
& $\begin{array}{l}\text { *Ship management company and } \\
\text { the ship are considered as one } \\
\text { subsystem. }\end{array}$ & \begin{tabular}{l} 
\\
\hline
\end{tabular} \\
\hline
\end{tabular}

\subsection{Accident reports}

Given the fast pace in technological change in ship design, it is reasonable to focus on recent accidents and serious incidents only. Additionally, the introduction of the International Safety Management (ISM) Code in 1998 has been transforming the way safety is maintained during operation. The twenty years period is relatively short for complete adoption of the new standard (Bhattacharya, 2012), and hence the later years would be more representative of the current situation. Hence, we focused on the last decade only.

As we were concerned to produce results that can be replicated and challenged by other researchers, we used only publically available accident investigation reports. In total, 188 reports were downloaded from 20 investigation boards (Figure 3). The set also included such notorious calamities as the sinking of Costa Concordia and MV Sewol. The largest number of the reports, 1/3 of the total, came from the UK Marine Accident Investigation Branch (MAIB). Nearly half of ships were Ro-Ro passenger ships and occupational accidents (crew or passenger injuries and fatalities) represented the leading accident category (Figure 3). We used only three suitability criteria for the located reports:

- $\quad$ Accidents or serious incidents for the period 2007 - 2017;

- Involve passenger ships ${ }^{3}$ : cruise ships, passenger ferries, mega yachts, and other passenger ships.

- Comply with the international investigation and reporting requirements, (EC, 2009; MSCMEPC.3/Circ.4/Rev.1, 2014; Res. MSC.255(84), 2008), or corresponding national ones, e.g. (BDT, 2012). The report contained such sections as a summary, factual information, accident narrative, analysis, conclusions and recommendations.

The ship size was not strictly limited, but the majority of the ships were of medium or large size (100 meters in length and above). We built an online database that stores all the used investigation reports and access can be granted to an interested reader by contacting the first author.

\footnotetext{
${ }^{3}$ Passenger ship is a ship carrying more than 12 passengers (the crew does not count).
} 

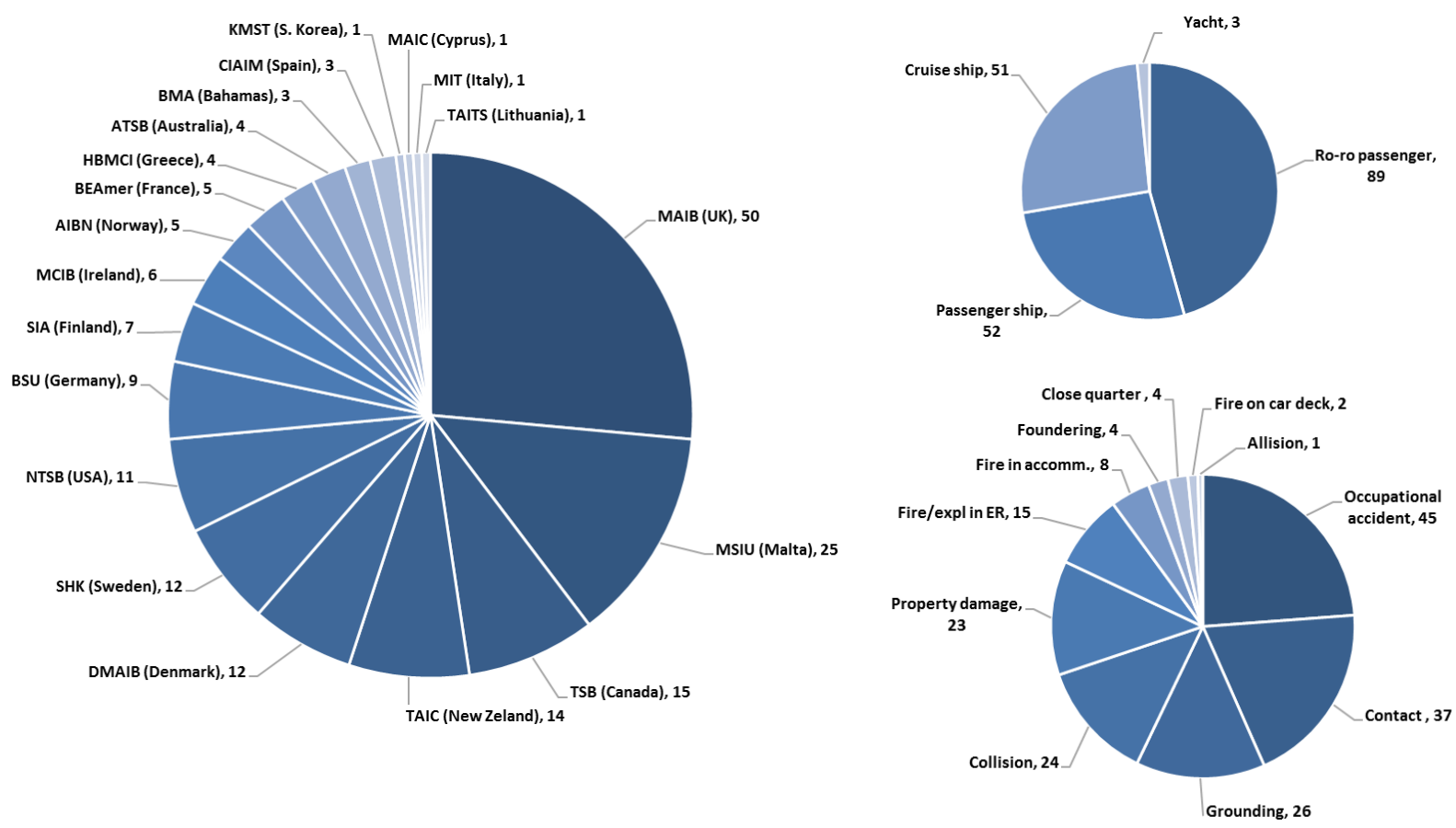

Figure 3: The number of accident investigation reports by investigation board (left), and distributions of ship type (top right) and accident/incident category (bottom right) across investigation reports.

The level of detail was dissimilar across the investigation reports. Some reports were very detailed and comprehensive (e.g., the Costa Concordia investigation by Italian MIT, 180 pages), others were more concise (e.g., MAIB reports of 40-70 pages), whereas other reports were quite brief (e.g., Maltese MSIU investigations of 5-10 pages). The type and scale of the accident clearly affected the extent of an investigation, but it may also have varied depending on the training of investigators and those who actually wrote the reports.

We recognise that investigation reports are an incomplete source of accident information, principally limited by a stopping rule applied by investigators and selectivity. Potentially, crucial details could have been overlooked, facts misinterpreted or twisted through use of hindsight bias, counterfactual reasoning, normative language, mechanistic reasoning and other cognitive biases (Dekker, 2002). Additionally, the interpretation of original reports may be indeed invalid. However, accident investigation reports are commonly used for further analysis, e.g. (Johnson and Holloway, 2007; Santos-Reyes and Beard, 2009), provided the analysts have a background in safety engineering and the analysis results are crosschecked, as has been done in this work. In our case, the analysis involved four researchers, two of them postdocs, one $\mathrm{PhD}$ student, and one professor in maritime safety. Importantly, accident investigation reports contain basic information - such as a timeline of proximate events, parties involved and their roles and interactions, etc.-necessary to begin the CAST analysis. In fact, the CAST method seems to have been developed with this standard information coming out from accident reports in mind. The application of CAST on standard investigation reports has been demonstrated to reveal - as will also be shown in this paper-additional causal factors, including extra proximate events, contributing events and, obviously, systemic causes (Kim et al., 2016a; Leveson, 2011).

\subsection{Illustrative analysis}

In this section, we illustrate the process of applying the described methodology to a sample incident. Cruiser Le Boreal experienced a serious fire in the engine room in 2015 (BEAmer, 2016). The fire broke out immediately following the erroneous replacement of a fuel filter. The filter was under pressure, for the engineer confused it with another filter (belonging to a different diesel generator) which was indeed clogged and needed replacing. The investigation concluded that "the engineer officer who carried out the replacement of a clogged fuel filter element had been presumably misled by a faulty visual memory and undertook the disassembly of an element under pressure" (BEAmer, 2016). That is, the investigators alluded to the human error. BEAmer recommended that the company consider the addition of a mechanic rating during the night watches and reengineering of the fuel system. The company made changes by forbidding solitary maintenance of the fuel feeding lines, migrating to a new generation of filters with a fuel pressure warning device and a purge valve, and installing a protection screen to prevent the contact between oil sprays and unprotected high temperature surfaces. 
At the physical level, the dysfunctional interaction between the engineer and the equipment (diesel generators, fuel filters, exhaust piping) was the direct cause of the incident. In particular, the control actions over of the hazardous equipment were inadequate. The reason why the engineer made this decision was related to the fact that there were no adequate feedback and prevention mechanisms in place to control the right sequence of actions. The absence of timely and accurate feedback led to an inconsistent mental model, i.e. the wrong understanding about the system state. Hence, the first question is why the feedback and prevention mechanisms were not in place? The investigation report indicates that the engineer carried out the maintenance without waiting for a mechanic rating coming in the morning. It would be reasonable to assume - and there is no contradiction in the report - that the engineer followed the established practice by taking this initiative. Hence, the question is why the safety management system (SMS) or management (Chief Engineer) allowed this risky practice? Alternatively, the engineer could have not well understood the safe maintenance procedures or his responsibilities. Hence, the question is why the engineer might not be familiar with the safe maintenance procedures or his responsibilities, did he receive adequate training? The explosion would not have happened had the surface of the turbo-blower exhaust elbow been properly thermo-insulated. The question is why the heat source was not timely detected and warned about, i.e. why the feedback about the hazard was missing? Were there objective or/and subjective factors that made the detection difficult? Did the engineers receive necessary training to detect such hazards in given circumstances?

More fundamental, systemic causes that help explain why an incident or accident happened were not mentioned in the report. Hence, they were inferred rather than found (Hollnagel, 2004). For instance, we inferred that the design limitation (unprotected hazard) with respect to maintenance of diesel generators had inadequately been communicated by the manufacture and consequently was not reflected in the safety management system (SMS). Otherwise, the shipping company (as in this particular example) would have reflected the design limitation in the SMS. There is no particular reason that the company would operate the vessel with such a serious hazard. Equally, there is no particular reason that the manufacturer would have not communicated the design limitation had they known about it, meaning that further causal factors such as the use of incomplete hazard analysis by the manufacture could be included.

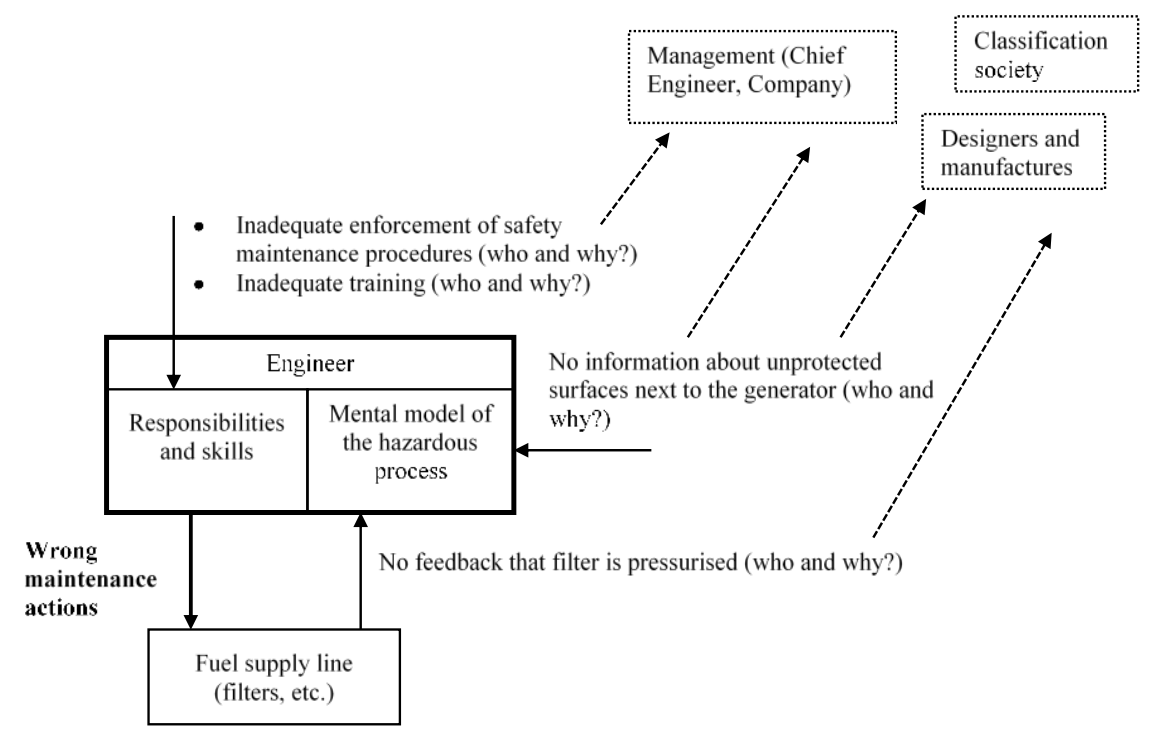

Figure 4: The starting point for the analysis

Figure 4 summarises dysfunctional interactions at the physical level, with the questions to be answered by analysing the related higher level controllers which are pointed to by the dashed arrows. An analogous diagram would be produced for each related higher level controller, asking why the control actions were inadequate by analysing feedback, its mental model and communication channels. Table 6 lists the identified dysfunctional interactions after exploring the entire GHCS, searching for the answers as to who was responsible for ensuring that the interactions are adequate and why they not happen. 
Table 6: Summary of dysfunctional interactions in safety control of the Le Boreal incident (symbols and abbreviations are explained in Table 4 Table 5)

\begin{tabular}{|c|c|c|c|c|c|c|}
\hline Controller & Controlled & $\begin{array}{l}\text { What } \\
\text { failed }\end{array}$ & $\begin{array}{l}\begin{array}{l}\text { Condition } \\
\text { (failure } \\
\text { mode) }\end{array} \\
\end{array}$ & Incl. & Description & $\begin{array}{l}\text { Cause } \\
\text { category }\end{array}$ \\
\hline Engineers & Machinery etc. & $\downarrow$ & $\mathrm{W}$ & $\mathrm{Y}$ & $\begin{array}{l}\text { Engineer attempted to switch filters } \\
\text { on the wrong generator }\end{array}$ & $\mathrm{D}$ \\
\hline Engineers & Machinery etc. & $\uparrow$ & $\mathrm{N}$ & $\mathrm{Y}$ & $\begin{array}{l}\text { Engineer was not prevented from } \\
\text { undertaking unsafe filter change } \\
\text { (absence of warning or a coding } \\
\text { system on the filter cover) }\end{array}$ & $\mathrm{D}$ \\
\hline Engineers & $\begin{array}{l}\text { Automatic and } \\
\text { passive } \\
\text { controllers } \\
\text { (insulation } \\
\text { etc.) }\end{array}$ & $\uparrow$ & $\mathrm{N}$ & $\mathrm{Y}$ & $\begin{array}{l}\text { Engineer was not informed about } \\
\text { poor holding of lagging cover (turbo- } \\
\text { blower exhaust elbow) which created } \\
\text { exposure to high temperature surface. }\end{array}$ & $\mathrm{D}$ \\
\hline $\begin{array}{l}\text { Chief } \\
\text { Engineer }\end{array}$ & Engineers & $\downarrow$ & $\mathrm{W}$ & $\mathrm{N}$ & $\begin{array}{l}\text { Chief Engineer did not made sure the } \\
\text { thermal insulation of turbo-blower } \\
\text { exhaust elbow was properly } \\
\text { maintained. Did not follow SMS. }\end{array}$ & $\mathrm{C}$ \\
\hline $\begin{array}{l}\text { Chief } \\
\text { Engineer }\end{array}$ & Engineers & $\downarrow$ & $\mathrm{N} / \mathrm{S}$ & $\mathrm{N}$ & $\begin{array}{l}\text { Chief Engineer did not made sure that } \\
\text { the maintenance manual of fuel filters } \\
\text { was strictly followed. }\end{array}$ & $\mathrm{C}$ \\
\hline $\begin{array}{l}\text { Ship } \\
\text { management } \\
\text { company }\end{array}$ & Ship & $\downarrow$ & $\mathrm{W}$ & $\mathrm{P}$ & $\begin{array}{l}\text { Not robust and vague safety } \\
\text { procedures with respect to routine } \\
\text { maintenance. Deficient SMS. }\end{array}$ & $\mathrm{C}$ \\
\hline $\begin{array}{l}\text { Ship } \\
\text { management } \\
\text { company }\end{array}$ & Ship & $\downarrow$ & $\mathrm{N}$ & $\mathrm{Y}$ & $\begin{array}{l}\text { Risk due to solitary undertaking of } \\
\text { maintenance at night was not } \\
\text { assessed and addressed in SMS. }\end{array}$ & $\mathrm{C}$ \\
\hline $\begin{array}{l}\text { Ship } \\
\text { management } \\
\text { company }\end{array}$ & Ship & $\uparrow$ & $\mathrm{N} / \mathrm{S}$ & $\mathrm{Y}$ & $\begin{array}{l}\text { Master did not well communicate the } \\
\text { understaffing (a rating was needed } \\
\text { during night watches in fuel } \\
\text { treatment compartment) }\end{array}$ & $\mathrm{C}$ \\
\hline $\begin{array}{l}\text { Project } \\
\text { management } \\
\text { (ship builder / } \\
\text { supplier) }\end{array}$ & $\begin{array}{l}\text { Design \& } \\
\text { documentation }\end{array}$ & $\downarrow$ & $\mathrm{W}$ & $\mathrm{Y}$ & $\begin{array}{l}\text { Coding system, interlock, or warning } \\
\text { mechanism was not provided on the } \\
\text { fuel filter covers to prevent } \\
\text { maintenance errors. }\end{array}$ & $\mathrm{C}$ \\
\hline $\begin{array}{l}\text { Project } \\
\text { management } \\
\text { (ship builder / } \\
\text { supplier) }\end{array}$ & $\begin{array}{l}\text { Design \& } \\
\text { documentation }\end{array}$ & $\downarrow$ & $\mathrm{W}$ & $\mathrm{N}$ & $\begin{array}{l}\text { Safety requirements, analysis } \\
\text { methods were inadequate, } \\
\text { overlooking the materialised } \\
\text { maintenance hazard. }\end{array}$ & $\mathrm{C}$ \\
\hline $\begin{array}{l}\text { Ship builder / } \\
\text { supplier }\end{array}$ & $\begin{array}{l}\text { Ship } \\
\text { management } \\
\text { company }\end{array}$ & $\downarrow \uparrow$ & $\mathrm{N}$ & $\mathrm{N}$ & $\begin{array}{l}\text { No communication of design } \\
\text { limitation / unprotected hazard with } \\
\text { respect to maintenance of diesel } \\
\text { generators. This was therefore not } \\
\text { addressed in the SMS. }\end{array}$ & $S$ \\
\hline
\end{tabular}

The shaded rows in Table 3 correspond to the interactions that were overlooked in the accident investigation report. In particular, these are three contributing factors and one systemic factor. The CAST analysis pointed to these contributing factors, which involved the chief engineer, by taking into account his responsibilities and the functional relationships in the GHCS. The systemic causal factor, which violated system safety constrains C1 and C3 (Table 3), were inferred by exploring the functional links to the designers / manufacturers.

The graphical representation of the dysfunctional interactions is shown in Figure 5. The blue lines indicate the interactions identified in the investigation report, the red ones denote the ones which were added through the CAST analysis, whereas the amber lines contain both. The numbers next to the links denote the number of instances (across the accident reports; only one in this case) where this control/feedback was inadequate. For instance, the engineer applied one wrong control action on the machinery, and there was single missing feedback to timely inform the right 
action. Also, the engineer did not receive feedback from the automatic and passive controller on the state of the lagging cover.

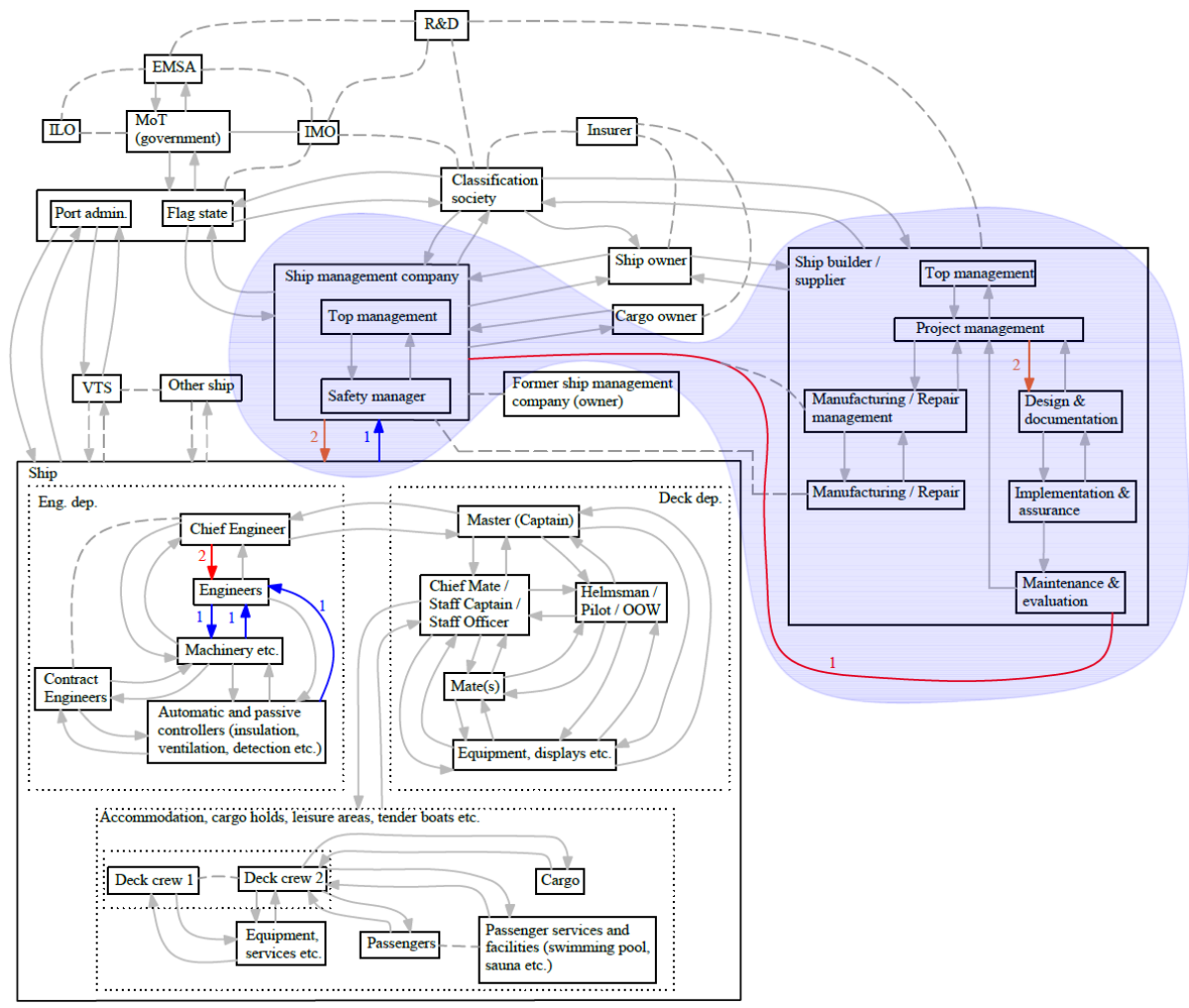

Figure 5: Dysfunctional interactions that led to Le Boreal incident

The shaded area in Figure 5 encloses the subsystems whose dysfunctional interactions gave rise to systemic causes behind the incident. The end result of these dysfunctional interactions was the deficient SMS, for it had not catered for the hazardous scenario that materialised. The presence of a single dysfunctional interaction between the manufacturer and the shipping company means that this was assumed to happen once during the handover of the new vessel.

It should be noted the performed analysis of the Le Boreal incident could, in principle, have included other elements of the hierarchical control structure, such as the maritime administration and classification society. For instance, why surveys and audits did not recognise the solitary maintenance as hazardous? However, we felt the evidence of the wide causal picture was very weak in this particular case. This cautious approach was applied in in the complete analysis as well. Hence, the CAST analysis was somewhat conservative.

\section{Results}

\subsection{General classification}

The dysfunctional interactions were classified as described in Section 3.1 and shown in Figure 6 to Figure 9. 


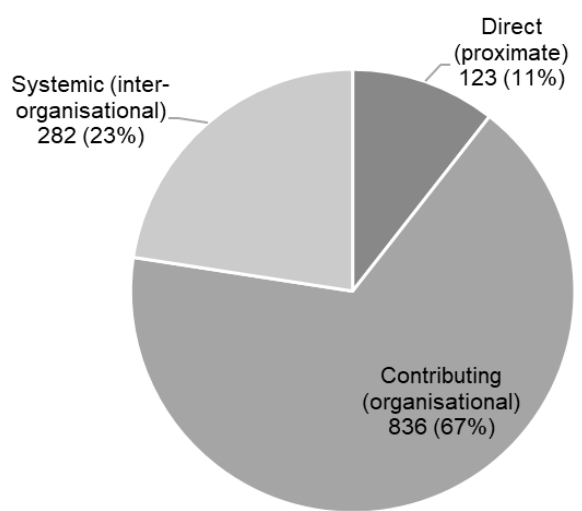

Figure 6: Shares of identified dysfunctional interactions across the three causal categories

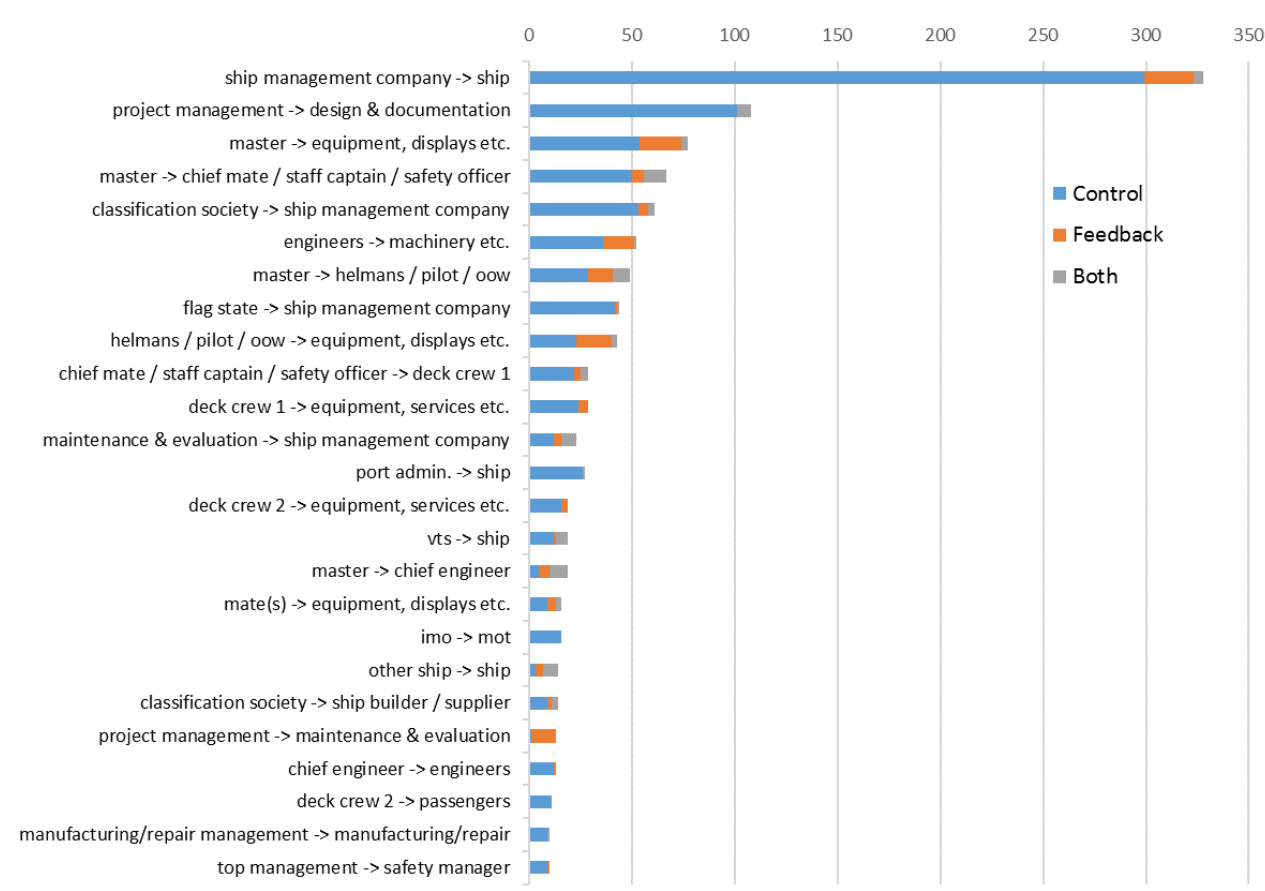

Figure 7: Distribution of causes of dysfunctional interactions (what/who failed). The arrows indicate the direction of control. 


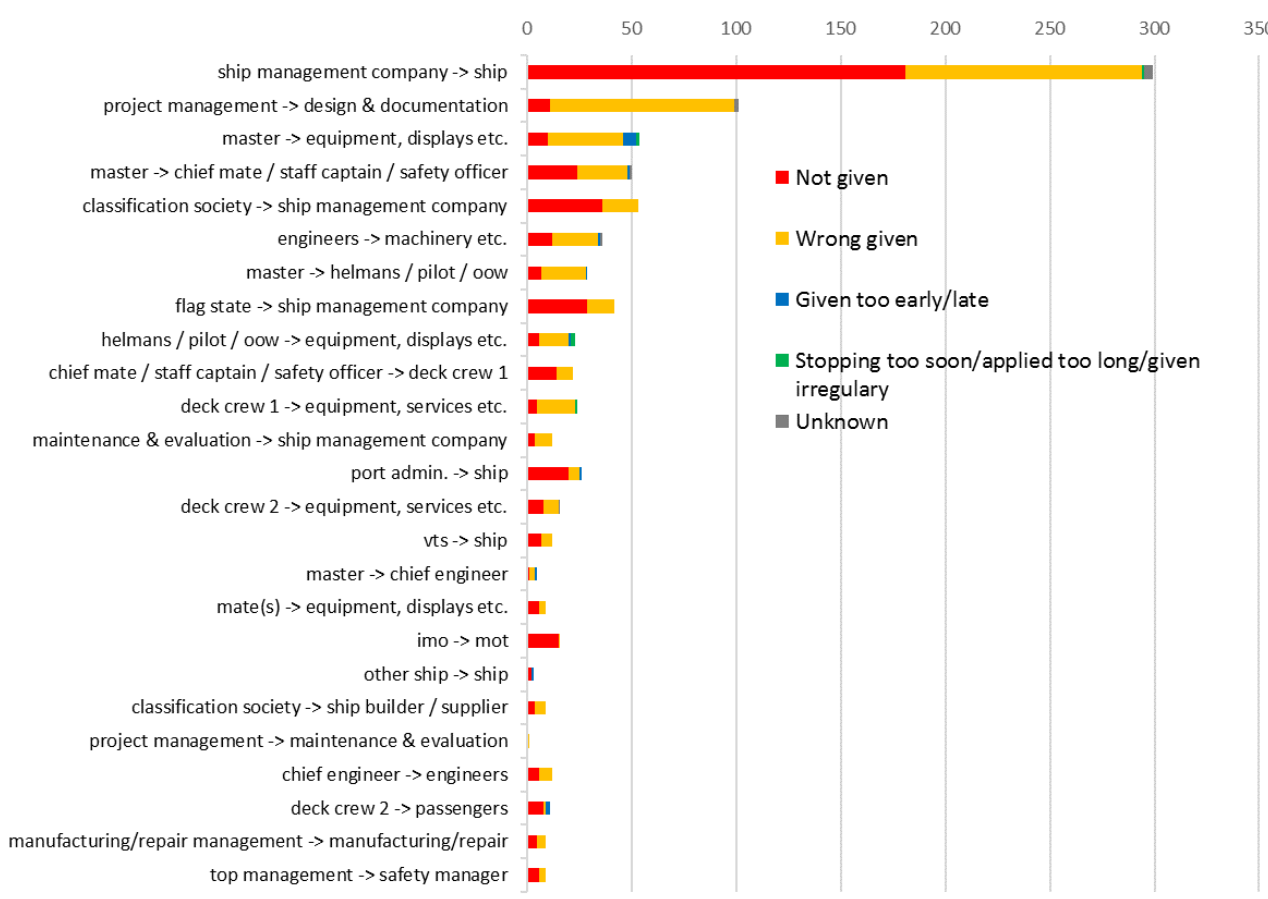

Figure 8: Distribution of conditions that made control dysfunctional (failure modes of controls)

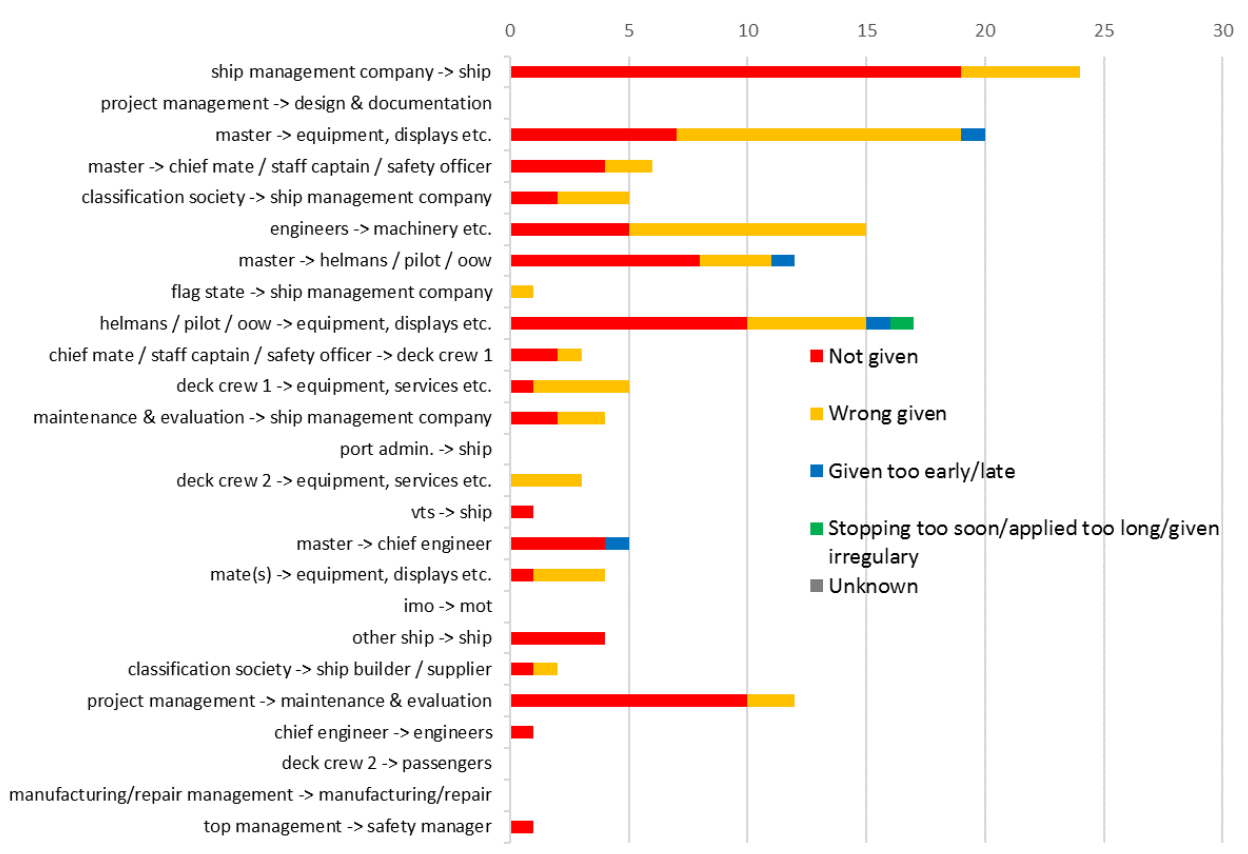

Figure 9: Distribution of conditions that made feedback dysfunctional (failure modes of feedbacks)

The dysfunctional interactions were mapped into the generic safety control structure shown in Figure 10. The arrows are colour coded to improve readability and distinguish between different frequencies of dysfunctional interactions across all investigation reports. Thus, the bright red lines indicate the highest frequency $(>100)$, blur red $(>50)$, orange (>30) and so on, finishing with the grey having the lowest frequency. The subsequent graphs (Figure 7 to Figure 9) outline the hierarchical classification of dysfunctional interactions described in Table 4; only 26 most frequent interactions are listed. 


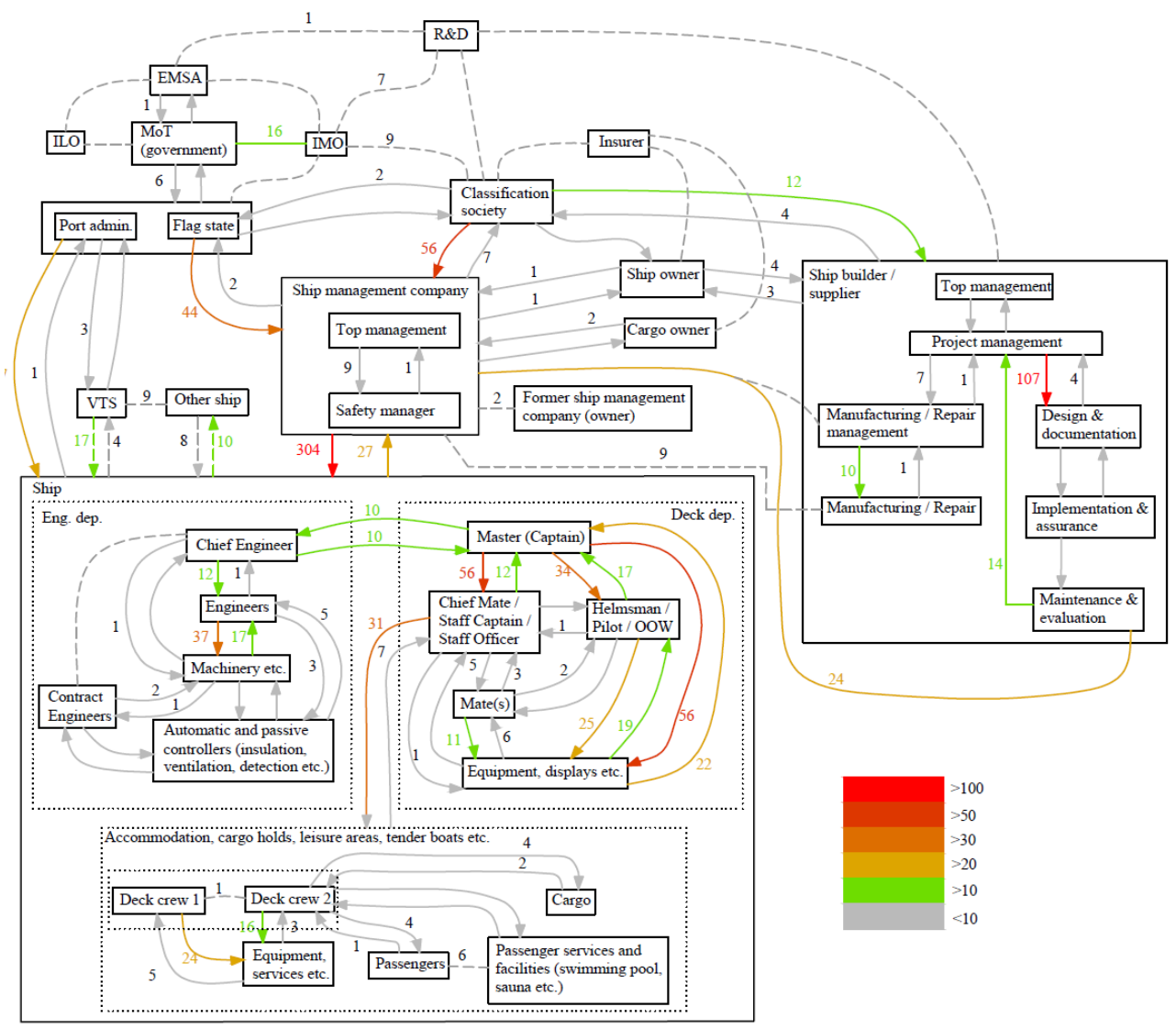

Figure 10: Summary of dysfunctional interactions (frequencies across all reports are given)

The direct factors (proximate events) are clearly seen within engineering and deck departments in Figure 10, where interface failures - of controls and feedback (Figure 7) - between engineers/bridge crew and machinery/navigation equipment are shown. The dominant direct cause is related to the inadequate control by crew (e.g., master $\rightarrow$ chief mate, master equipment, helmsman etc. $\rightarrow$ equipment), with the frequent presence of inadequate feedback from equipment. The deficient communication between the crew members (e.g., between the master and other officers) is one of the most frequent causal factors. The contributing factors, such as inadequate training, supervision, or management in general, are observable within the ship subsystem and in the interaction with the company. The latter interaction is the foremost frequent causal factor across all investigation reports (appeared 304 times). The dysfunctional interactions at the system level are addressed in the next subsection.

\subsection{Prevailing systemic factors}

Given the system safety constraints (Table 3), there were many dysfunctional interactions on the overall system level (i.e., between subsystems) that gave rise to systemic causes or explanations as to way the incidents and accidents happened. Such systemic factors are shown in Figure 11 and Figure 12, where the shaded areas enclose subsystems and their interactions that constituted systemic causal factors. 


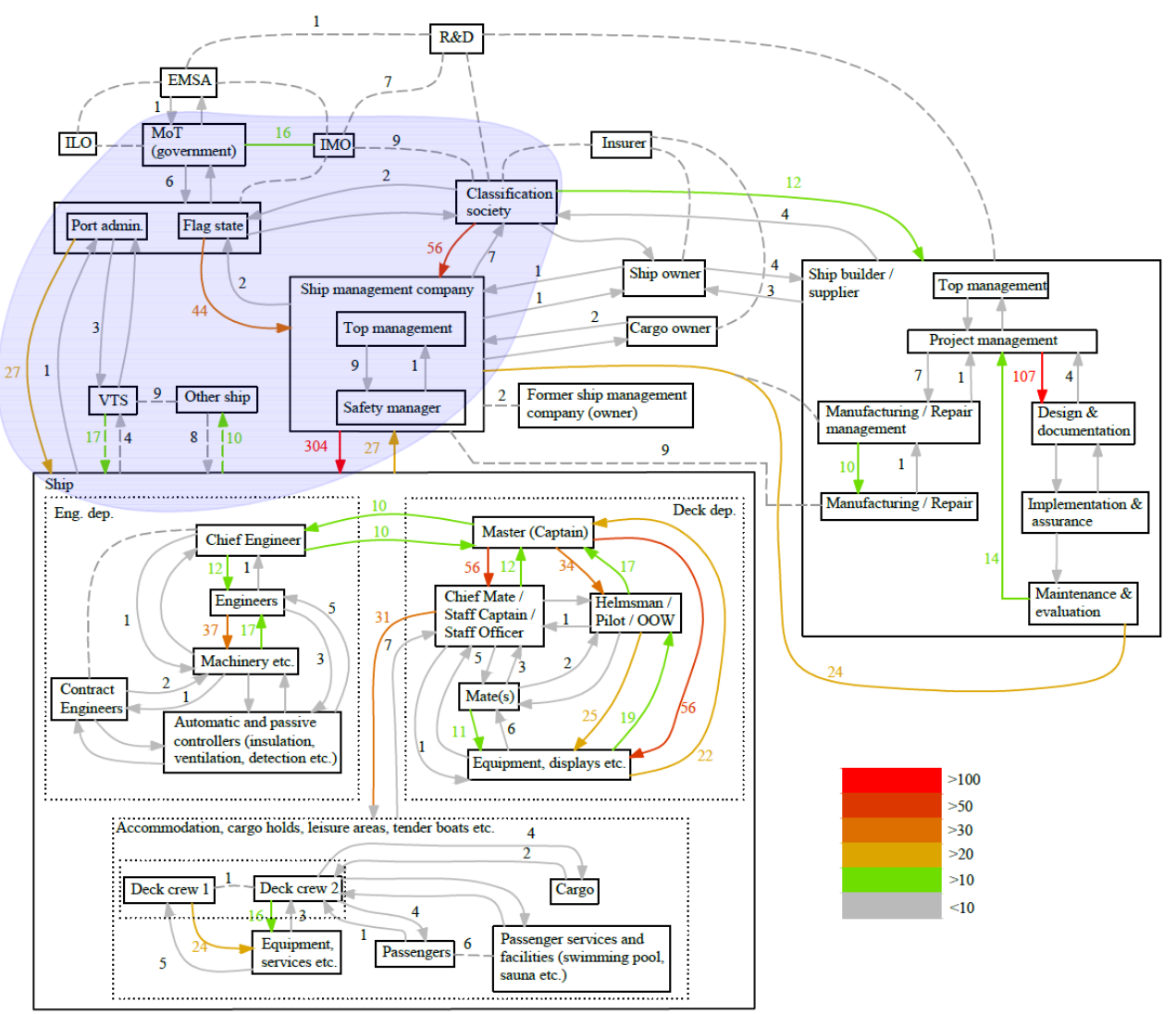

Figure 11: $1^{\text {st }}$ subset of subsystems and interactions between them that gave rise to the systemic causes

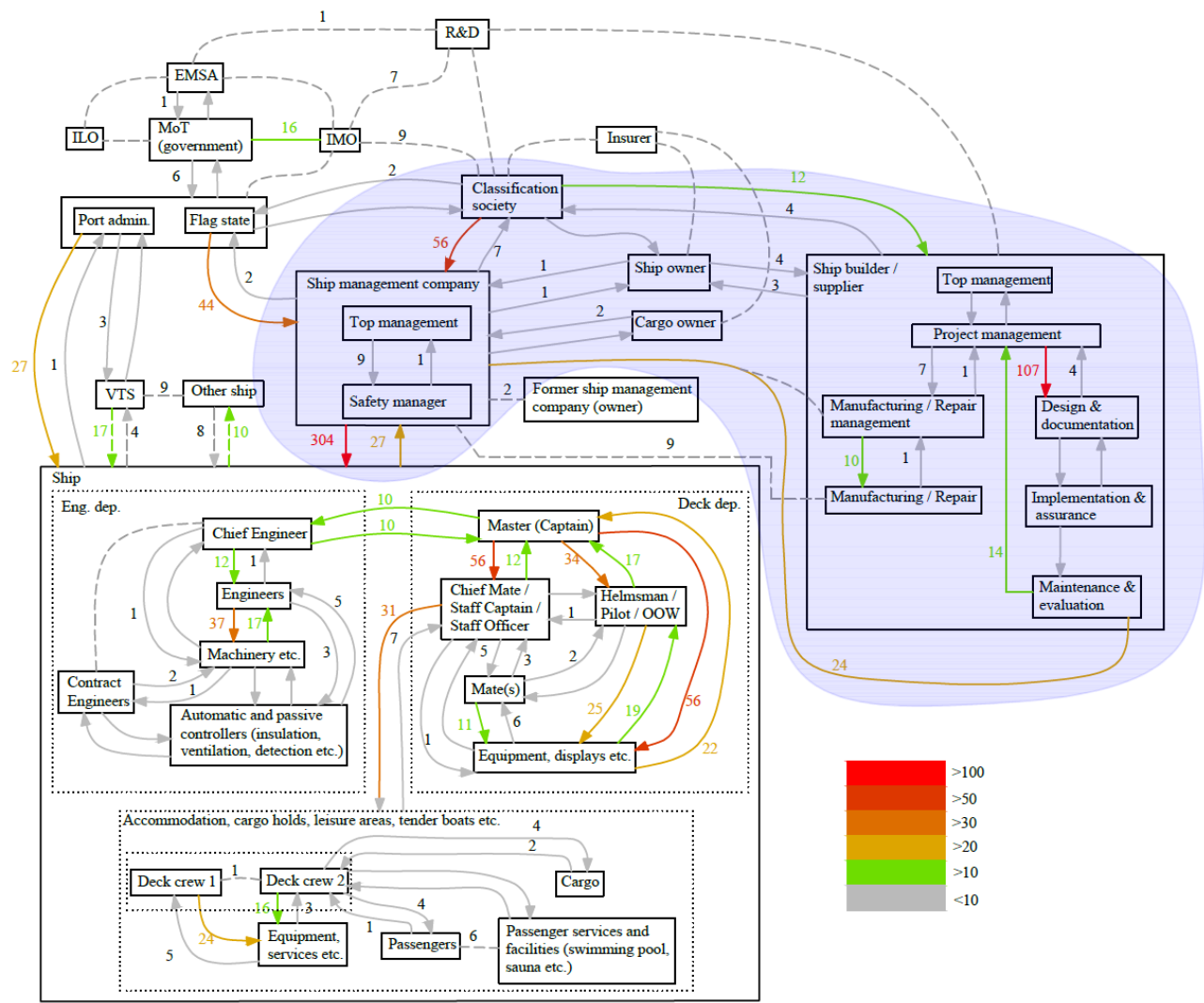

Figure 12: $2^{\text {nd }}$ subset of subsystems and interactions between them that gave rise to the systemic causes 
The first set represents systemic factors that violate the system constraint $C 4$. The presence of inadequate regulatory control from flag states and classification societies (Figure 11 and Figure 7) was not particularly helpful in developing and maintaining a well risk-informed and cost-effective SMS by the company. The absence of adequate control from regulators, as the results indicate, and the natural management pressure towards cost effective operation (Rasmussen, 1997), could - when working together-insidiously lead to the high frequency of dysfunctional control between the company and the ship. We also found that an important part of this picture of systemic causes were gaps in safety regulations by IMO, as Figure 11 also shows, not the least in relation to the ISM Code which is considered lax (Kristiansen, 2005). Note, that the frequencies in dysfunctional interactions between the company and regulators are lower compared to the frequency between the company and the ship. This may be explained by the nonlinear, background effect of the lax safety control of the company decisions.

The second set (Figure 12) encloses other systemic factors that violate the rest of the system constraints: $C 1, C 2$ and $C 3$. The earlier discussed deficiency in the design process where safety hazards got overlooked is an important element of systemic causes, but only if it works together with other factors such as inadequate communication of design limitations to the company-subsequently leaving unattended safety hazards in the SMS (recall the Le Boreal incident) - and inadequate regulatory function by classification societies. These dysfunctional interactions ultimately led to the fragile SMS. The inadequate hazard identification in design was frequently alluded to in the accident reports or inferred during the CAST analysis. Whereas, the presence of dysfunctional communication between the company and the shipbuilder could only be justifiably identified in 24 cases, as show in Figure 12. However, it would be correct to assume that this communication channel failed more frequently, or there was another nonlinear effect of this dysfunctional interaction on the robustness of the SMS or proximate events.

\subsection{Gap analysis}

In most cases, all direct and indirect causal factors would be mentioned in the accident investigation reports (Figure 13 and Figure 14). However, the frequency of omission remains relatively high in absolute terms (e.g., the top two interactions) and in relative values for many interactions (Figure 15). Hence, the omissions are observable amongst direct, contributing and systemic factors in particular. The latter included such interactions as: ship management company $\rightarrow$ ship, classification society / flag state / VTS / other ship $\rightarrow$ company / ship, IMO $\rightarrow$ MoT, classification society $\rightarrow$ manufactures, etc. The highest rate of omission corresponds to the interactions being outside the ship and shipping company, which are the two main elements of the system considered in accident investigations.

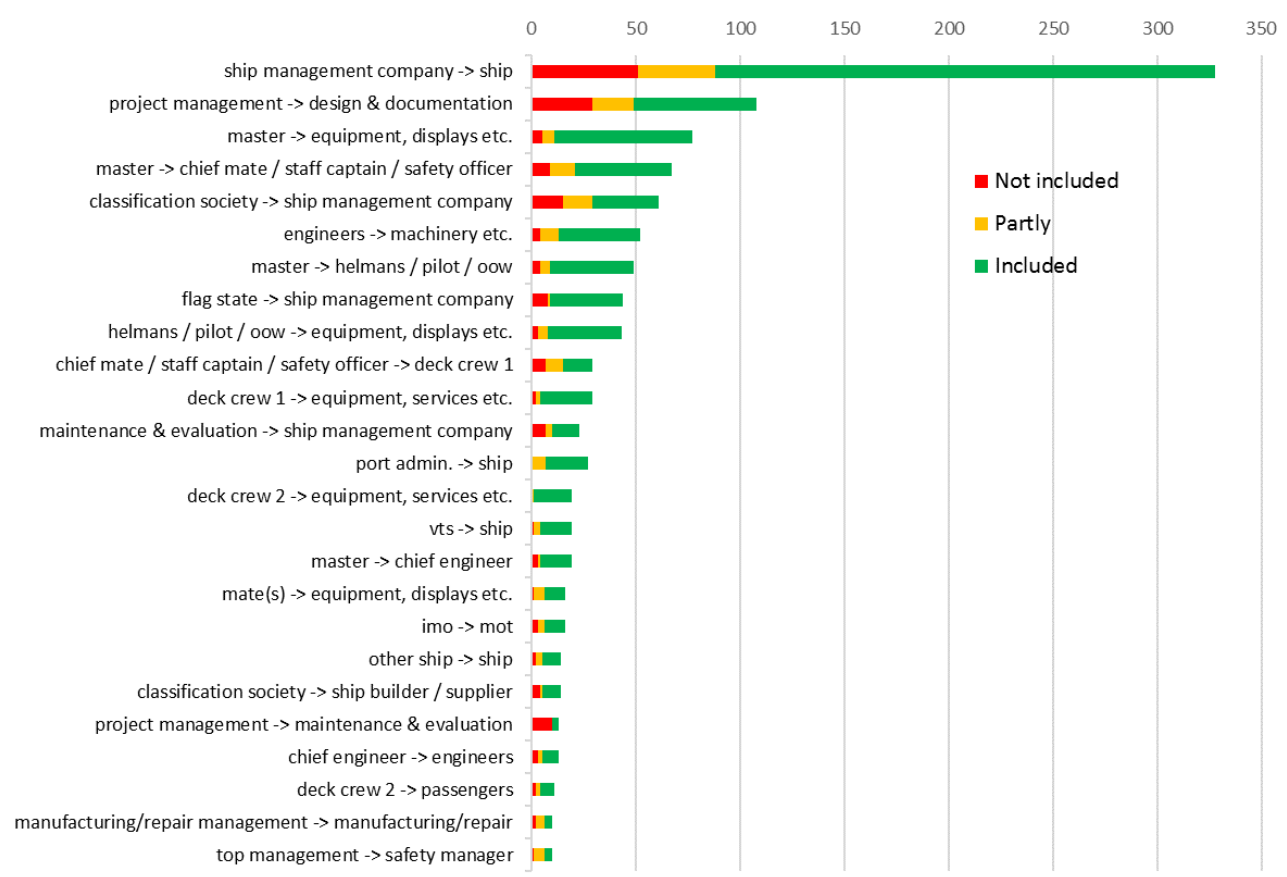

Figure 13: Distribution of inclusion of identified dysfunctional interactions in investigation conclusions (absolute values) 


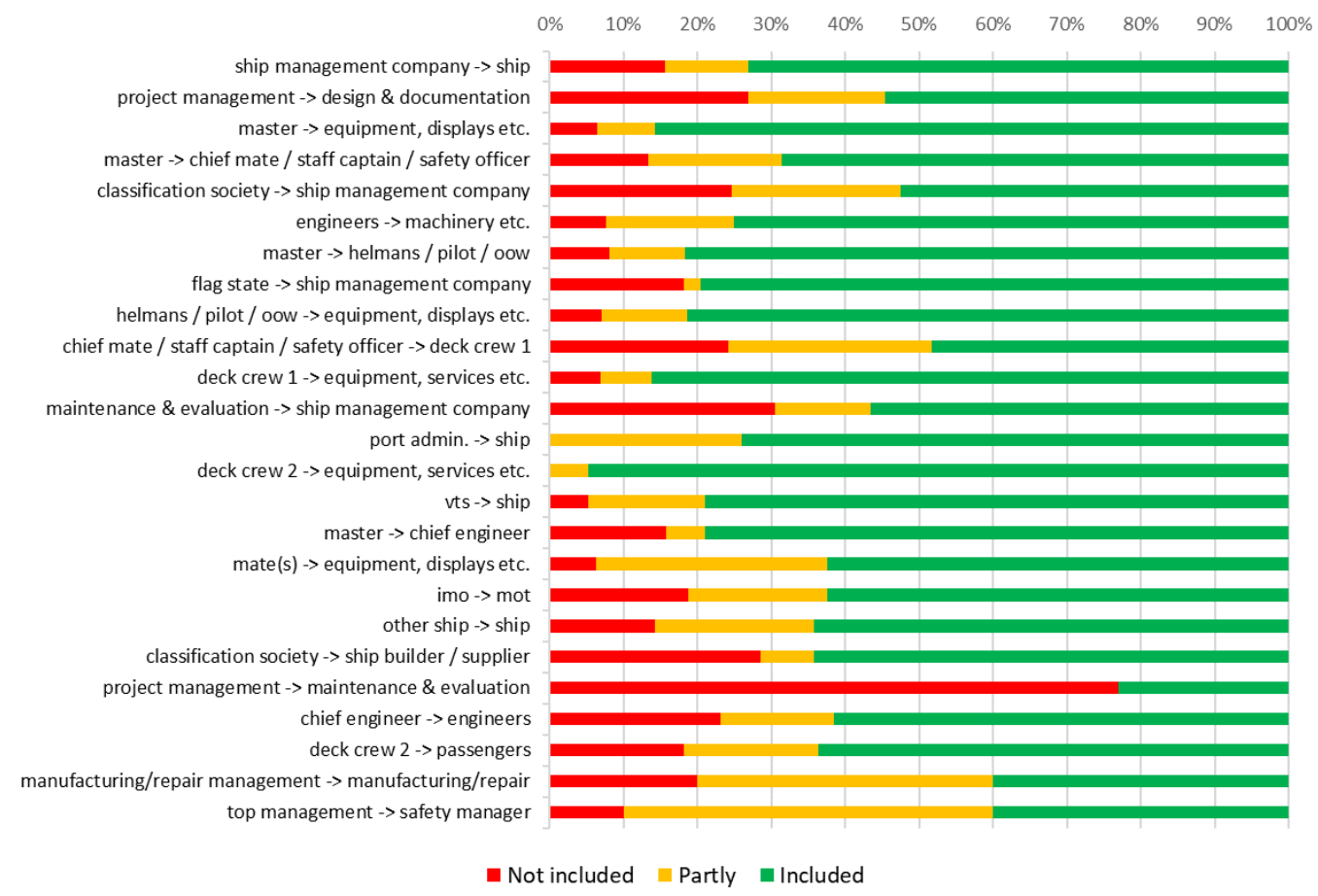

Figure 14: Distribution of inclusion of identified dysfunctional interactions in investigation conclusions (relative values)

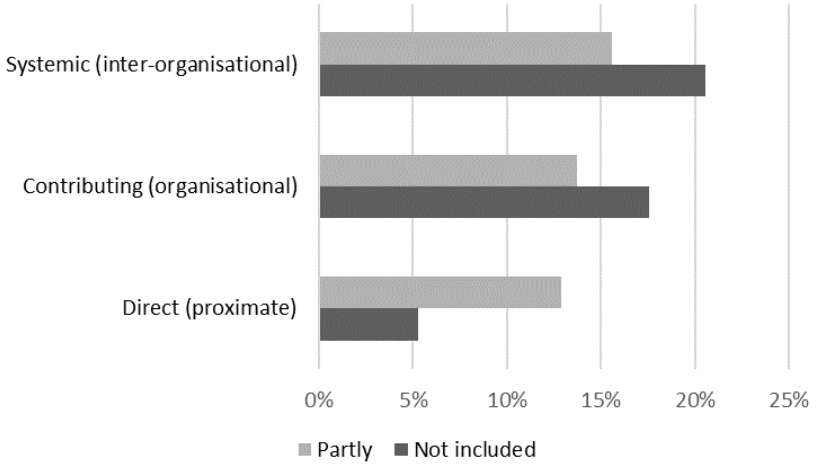

Figure 15: Share of omission across causal categories

\section{Discussion}

It is worth recalling the systems view on accident causation, which states that accidents occur when interactions between and within the system elements are controlled inadequately. The presented analysis identified and weighed such dysfunctional interactions within the system. In the following, we limit our discussion to the most prominent and important, in our view, interactions at the organisation and system levels.

The deficiency in control and feedback mechanisms between the ship management company and the ship, is the most prominent (304 records). This interaction is at the organisational level, but may well be considered as systemic, for a shipping company normally manages many loosely dependent ships (subsystems). The primary causes for the dysfunctional interface lay in the absence of control or the presence of wrong control (Figure 7 and Figure 8). This points to loopholes in the SMS, with hazards (risks) overlooked, presence of insufficient training, and inaccurate, untimely reporting to the company of problems on the ship. That is, inadequate feedback on skill, results of risk assessments etc. to the company forms a wrong mental model about the actual situation onboard, which leads to inadequate control by the company (e.g., insufficient training). It appears that the safety management objectives of the company as per the ISM Code (Paragraph 1.2.2) — such as "Assess all identified risks to its ship, personnel, and the environment, and establish appropriate safeguards" and "Continuously improve safety management skills of 
personnel ashore and aboard ships"- have been difficult to achieve. This observation agrees with results of related studies, e.g. (Batalden and Sydnes, 2014).

Another prominent dysfunctional interaction was within the ship design and manufacturing context. We specifically denoted this as the interaction between the project management and design \& documentation teams. This causal factor would typically be related to incomplete hazard analysis, i.e. some safety hazards during design would be overlooked. This would be subtle hazards that would remain dormant until some unforeseen events trigger them; the incident with cruise ship Le Boreal (Section 3.4) is a case in point. Example instances of inadequate hazard elimination and control at the design stage are (many of them was stated in the investigation reports):

- The bilge alarm was not in steering gear/storage compartment.

- Inadequate safety requirements and constraints (Operations Manual) when it comes to risks involved with the pilot ladder arrangements.

- There were no effective means for the hydraulic system of controlled pitch propeller to relieve excess pressure in the event that the back pressure valve failed.

- Insufficient safety requirements with respect to bridge layout design.

- Provision of insufficient safety requirements and oversight with respect to installation of light fixtures (fluorescent light) on car decks.

- Design of fin stabiliser panel on the bridge centre console did not provide adequate feedback (warning etc.) about the hazard when in the manual mode.

- The rails were designed without considering the risk of falling during mooring.

- Significant hazard of child failing overboard was not taking into account.

- The control was designed so, that once back-up control is activated, every attempt to control the propulsion was bypassed.

- The system did not alert about the mode when moving slower than a particular speed in "Sea Mode".

The design issues would often be overlooked unsafe system states (hazards) that involve various interactions, not least the interactions between technology and people, e.g. (Rokseth et al., 2017). New hazard analysis methods, which are not yet imbedded in the current requirements, could be considered for more comprehensive analysis. For instance, Systems Theoretic Process Analysis (STPA) is based on STAMP (Leveson, 2011) and it shows very promising results when it comes to identifying hazards in modern software intensive systems, or cyber physical systems, which are part of a complex socio-technical context. The method is already practiced by some industries and can be used to achieve compliance with new safety standards (Mallya et al., 2016).

An important systemic factor is the dysfunctional interactions between the regulators (classification society and flag state) and the company and ship. In absolute terms, these interactions were frequent but not dominant. In this case, the required regulatory control was not provided in the majority of cases, whereas the feedback from the company, i.e. the information about the state of safety management, was mainly wrong. Example instances of unsafe control on the part of classification societies are (many of them were directly stated in the investigation reports):

- Did not ensure that the risk assessment for swimming pool operations has been provided.

- Update on an SMS revision was not requested and its implementation checked.

- Did not ensure that the crew is properly familiarised with the SMS.

- The extensions provided by the classification society allowed for the vessel to be operated with malfunctioning control system for a long time.

- No enforcement of regulation with respect to electric fires.

- Did not ensure that the company and crew fully comply with the SMS procedures during navigation in dangerous areas.

- Approved the vessel without ensuring that the low pressure section of the fuel system was screened off.

- The implementation of proper planned maintenance system by the company was not ensured.

- Did not provide comprehensive guidance to its surveyors with regard to examining thermal oil heaters.

Such unsafe control was driven by internal interactions - which were not analysed - within classification societies and external communication with the company, ship and others. For instance, in one of the cases a classification society was not informed about structural modifications to the vessel and, therefore, wrongly assumed the compliance. 
Another important systemic factor identified was the flawed communication between manufacturers and ship management companies, as exemplified in Section 3.4. Poor communication of design limitations means they are not adequately reflected in the ship's SMS and, therefore, the ship will be operated differently as was assumed during design. The deviation from design assumptions, given they are correct, is a well-known causal factor behind many accidents (Leveson, 2015). Therefore, the company must make sure that all design assumptions and limitations, as well as any deviations during manufacturing, are well documented and communicated to the company. This should be achievable for newbuilding projects and for some ships in the fleet. Additionally, the development of the SMS must consider realistic circumstances such as the natural gradient towards least effort by crew, ubiquitous push for cost effectiveness, and natural work variability (Hollnagel, 2016; Rasmussen, 1997). The understanding of where the safety boundaries are is a key strategy to achieving both safety and cost effectiveness, for the former is maximised on safety fringes (Rasmussen, 1997). Corresponding safety constraints will need to be developed and reflected in the SMS in terms of responsibilities, accountabilities, control and necessary feedback mechanisms. Systemic methods such as STAMP can be used to achieve that.

\section{Conclusions}

Lessons from major maritime accidents are used to inform changes in design and operation of ships. Such a process of evolutionary improvement in safety is only as effective as the explanation of accident causes is. This study has shown that existing accident analysis is limited in explaining as to why an accident has happened, primarily focusing on what happened and who was at fault. Therefore, this study has attempted to illuminate the role of the wider sociotechnical context that was giving rise to causal mechanisms behind recent incidents and accidents with passenger ships. In summary, the paper has made the following contributions:

- We analysed 188 incident and accident reports and identified 1,250 instances of dysfunctional interactions within the system of maritime safety control. We classified these interactions according to their cause (control, feedback or both), condition that made them dysfunction (control/feedback not given, wrong given, given too later, etc.) and causal category (direct, contributing and systemic). Then we mapped the identified interactions onto a functional model of maritime safety control to highlight its weakest links and be used to suggest likely explanations behind maritime accidents.

- We discussed the systemic causal factors, underlying causal mechanisms that could insidiously degrade safety management systems, or, in general, various types of safety barriers such as organisational, technical and others.

- The classification of dysfunctional interactions also included the degree of their omission in the accident investigation reports. This allowed to perform a gap analysis of which results have also been presented. In most cases, all direct and contributing causal factors would be mentioned in the accident investigation. However, the frequency of omission remains relatively high for all three causal categories, for systemic factors in particular.

By examining the analysis results, the following observations and recommendations can be made:

- Deficiencies in the SMS, such as overlooked safety hazards, insufficient training, inadequate feedback to the company etc., were the most frequent contributing causes behind analysed accidents and incidents. Some immediate improvements in the SMS have been suggested, but the highlighted systemic causes have to be addressed to eliminate conditions leading to the flawed SMS.

- One of such improvements is related to hazard analysis in design. The study has shown that many accidents and incidents resulted from unidentified hazards of which some were not subsequently communicated to the operator. We have made suggestions how this problem can be addressed.

- The role of individual failures (human error and equipment failures) was marginal, giving way to organisational (contributing factors) and systemic causes. This observation agrees with conclusions in earlier studies (Johnson and Holloway, 2007).

- The presented study can be used to inform the development of proactive safety management, in particular the development of leading safety indictors at the ship, company, and overall system levels.

There are two notable caveats to the presented study. First, accident investigation reports were used as the sole information source. This is not, however, an unusual practice, provided mitigation measures are in place, as explained in Section 3.3. Second, CAST is a worst-case analysis method, not a best-case or most-likely-case method. Being a worst-case, qualitative method, CAST considers causal scenarios exhaustively, although, in the best-case, some of 
them might have not happened at all. However, having an exhaustive list of causal scenarios is obviously more beneficial, although is also costlier.

\section{Acknowledgement}

We would like to thank our colleague Stuart Williams for sharing his knowledge on maritime safety and providing valuable feedback to this study.

\section{References}

Batalden, B.-M., Sydnes, A.K., 2014. Maritime safety and the ISM code: a study of investigated casualties and incidents. WMU Journal of Maritime Affairs 13, 3-25.

BDT, 2012. The Merchant Shipping (Accident Reporting and Investigation) Regulations 2011, 2012. British Department for Transport, London.

BEAmer, 2016. Marine safety investigation report. Fire in the engine compartment on board the expedition-cruiser liner Le Boreal on 18 November 2015, off Falkland Islands. Bureau d'enquêtes sur les événements de mer (BEAmer).

Benner Jr, L., 1985. Rating accident models and investigation methodologies. Journal of Safety Research 16, 105 126.

Bhattacharya, S., 2012. The effectiveness of the ISM Code: A qualitative enquiry. Marine Policy 36, 528-535.

Carroll, J.S., 1998. Organizational learning activities in high-hazard industries: the logics underlying self-analysis. Journal of Management studies 35, 699-717.

Celik, M., Cebi, S., 2009. Analytical HFACS for investigating human errors in shipping accidents. Accident Analysis \& Prevention 41, 66-75.

Chauvin, C., Lardjane, S., Morel, G., Clostermann, J.-P., Langard, B., 2013. Human and organisational factors in maritime accidents: Analysis of collisions at sea using the HFACS. Accident Analysis \& Prevention 59, $26-37$.

Chen, S.-T., Wall, A., Davies, P., Yang, Z., Wang, J., Chou, Y.-H., 2013. A Human and Organisational Factors (HOFs) analysis method for marine casualties using HFACS-Maritime Accidents (HFACS-MA). Safety Science 60, 105-114.

Dekker, S., 2014. The field guide to understanding'human error'. Ashgate Publishing, Ltd.

Dekker, S., 2016. Just culture: Balancing safety and accountability. CRC Press.

Dekker, S.W., 2002. Reconstructing human contributions to accidents: the new view on error and performance. Journal of Safety Research 33, 371-385.

EC, 2009. DIRECTIVE 2009/18/EC.

EMSA, 2017. Annual Overview of Marine Caualties and Incidents 2017. European Maritime Safety Agency.

Hollnagel, E., 2004. Barriers and accident prevention: or how to improve safety by understanding the nature of accidents rather than finding their causes. Hampshire: Ashgate.

Hollnagel, E., 2016. Barriers and accident prevention. Routledge.

Johnson, C.W., Holloway, C.M., 2007. A longitudinal analysis of the causal factors in major maritime accidents in the USA and Canada (1996-2006). The Safety of Systems, 85-104.

Johnson, W.G., 1980. MORT safety assurance systems. Marcel Dekker Inc.

Kim, T.-e., Nazir, S., Øvergård, K.I., 2016a. A STAMP-based causal analysis of the Korean Sewol ferry accident. Safety Science 83, 93-101.

Kim, T.-e., Nazir, S., Øvergård, K.I., 2016b. A STAMP-based causal analysis of the Korean Sewol ferry accident. Safety Science 83, 93-101. 
KMST, 2014. 여객선 세월호 전복사고 특별조사 보고서 [Safety Investigation Report of MV Sewol]. Korean Maritime Safety Tribunal.

Kristiansen, S., 2005. Maritime transportation: safety management and risk analysis.

Kristiansen, S., 2010. A BBN approach for analysis of maritime accident scenarios, ESREL, Rhodes, Greece.

Lee, S., Moh, Y.B., Tabibzadeh, M., Meshkati, N., 2017. Applying the AcciMap methodology to investigate the tragic Sewol Ferry accident in South Korea. Applied Ergonomics 59, 517-525.

Leveson, N., 2011. Engineering a safer world: Systems thinking applied to safety. MIT press.

Leveson, N., 2015. A systems approach to risk management through leading safety indicators. Reliability Engineering \& System Safety 136, 17-34.

Leveson, N.G., Daouk, M., Dulac, N., Marais, K., 2003. Applying STAMP in accident analysis.

Leveson, N.G., Dulac, N., Barrett, B., Carroll, J., Cutcher-Gershenfeld, J., Friedenthal, S., 2005. Risk analysis of NASA independent technical authority. Cambridge, MA.

Lundberg, J., Rollenhagen, C., Hollnagel, E., 2009. What-You-Look-For-Is-What-You-Find - The consequences of underlying accident models in eight accident investigation manuals. Safety Science 47, 1297-1311.

Mallya, A., Pantelic, V., Adedjouma, M., Lawford, M., Wassyng, A., 2016. Using STPA in an ISO 26262 Compliant Process. Springer International Publishing, Cham, pp. 117-129.

Mazaheri, A., Montewka, J., Kujala, P., 2016. Towards an evidence-based probabilistic risk model for shipgrounding accidents. Safety Science 86, 195-210.

MIT, 2013. Cruise Ship COSTA CONCORDIA. Marine casualty on January 13, 2012. Report on the safety technical investigation. MINISTRY OF INFRASTRUCTURES AND TRANSPORTS.

MSC-MEPC.3/Circ.4/Rev.1, 2014. Revised harmonized reporting procedures - Reports required under SOLAS regulations I/21 and XI-1/6, and MARPOL, articles 8 and 12. IMO, London.

Pitblado, R., Fisher, M., Nelson, B., Fløtaker, H., Molazemi, K., Stokke, A., 2016. Concepts for dynamic barrier management. Journal of Loss Prevention in the Process Industries 43, 741-746.

Rasmussen, J., 1997. Risk management in a dynamic society: a modelling problem. Safety Science 27, $183-213$.

Reason, J., 1997. Managing the risks of organizational accidents.

Res. MSC.255(84), 2008. Adoption of the Code of the International Standards and Recommended Practices for a Safety Investigation into a Marine Casualty or Marine Incident (Casualty Investigation Code). IMO.

Rokseth, B., Utne, I.B., Vinnem, J.E., 2017. A systems approach to risk analysis of maritime operations. Proceedings of the Institution of Mechanical Engineers, Part O: Journal of Risk and Reliability 231, 53-68.

Salmon, P.M., Cornelissen, M., Trotter, M.J., 2012. Systems-based accident analysis methods: A comparison of Accimap, HFACS, and STAMP. Safety Science 50, 1158-1170.

Santos-Reyes, J., Beard, A.N., 2009. A systemic analysis of the Edge Hill railway accident. Accident Analysis \& Prevention 41, 1133-1144.

Schröder-Hinrichs, J.U., Baldauf, M., Ghirxi, K.T., 2011. Accident investigation reporting deficiencies related to organizational factors in machinery space fires and explosions. Accident Analysis \& Prevention 43, 1187-1196.

Shappell, S.A., Wiegmann, D.A., 2012. A human error approach to aviation accident analysis: The human factors analysis and classification system. Ashgate Publishing, Ltd.

Song, T., Zhong, D., Zhong, H., 2012. A STAMP analysis on the China-Yongwen railway accident. Computer safety, reliability, and security, 376-387.

STCW, 2010. International Convention on Standards of Training, Certification and Watchkeeping for Seafarers. IMO, London.

Stringfellow, M., 2010. Human and Organizational Factors in Accidents, sl. MIT. 
Svedung, I., Rasmussen, J., 2002. Graphic representation of accidentscenarios: mapping system structure and the causation of accidents. Safety Science 40, 397-417.

Svenson, O., 1999. On models of incidents and accidents, 7th European Conference on Cognitive Science Approaches to Process Control, Villeneuve d'Ascq, France, September, pp. 169-174.

Twomey, B., 2017. Making the case for safe autonomous marine cyber physical systems, Marine Electrical and Control Sytems Safety Conference (MECSS). IMarEST, Glasgow.

Underwood, P., Waterson, P., 2012. A critical review of the STAMP, FRAM and Accimap systemic accident analysis models. Advances in Human Aspects of Road and Rail Transportation. CRC Press, Boca Raton, $385-394$.

Underwood, P., Waterson, P., 2014. Systems thinking, the Swiss Cheese Model and accident analysis: A comparative systemic analysis of the Grayrigg train derailment using the ATSB, AcciMap and STAMP models. Accident Analysis \& Prevention 68, 75-94.

Wong, B., 2004. A STAMP model of the Überlingen aircraft collision accident. Massachusetts Institute of Technology.

Wróbel, K., Montewka, J., Kujala, P., 2017. Towards the assessment of potential impact of unmanned vessels on maritime transportation safety. Reliability Engineering \& System Safety 165, 155-169.

Wróbel, K., Montewka, J., Kujala, P., 2018. System-theoretic approach to safety of remotely-controlled merchant vessel. Ocean Engineering 152, 334-345. 